\title{
Generation of Functional Radial Glial Cells by Embryonic and Adult Forebrain Neural Stem Cells
}

\author{
Christopher Gregg and Samuel Weiss \\ Genes \& Development Research Group, University of Calgary, Faculty of Medicine, Calgary, Alberta, Canada T2N 4N1
}

\begin{abstract}
Radial glial cells (RGCs), a transient cell population present only in the developing CNS, function both as precursor cells and as scaffolds to support neuron migration. Their cellular origin, however, is not understood. In the present study, we tested the hypothesis that functional RGCs can be generated by multipotent neural stem cells. Embryonic forebrain neural stem cells were studied in vitro to identify putative signals that promote the generation and differentiation of functional RGCs, determined by their ability to support neuronal migration. Epidermal growth factor receptor signaling was sufficient to regulate both the generation and differentiation of morphologically, antigenically, and functionally defined RGCs. In contrast, fibroblast growth factor-2 promoted the generation of RGCs but was unable to support their differentiation. Although RGCs are not normally present in the adult brain, epidermal growth factor stimulated adult forebrain neural stem cells to generate RGCs in vitro and functional RGCs within the adult forebrain subependyma in vivo. Surprisingly, epidermal growth factor receptor signaling also promoted adult forebrain ependymal cells to dedifferentiate and adopt a radial morphology in vivo. These results suggest that neural stem cells can give rise to RGCs and that RGC-guided neuronal migration can be recapitulated in the adult CNS.
\end{abstract}

Key words: neural stem cell; radial glia; epidermal growth factor; fibroblast growth factor; neuron migration; regeneration

\section{Introduction}

During development of the murine telencephalon, the germinal zone contains a population of specialized cells called radial glial cells (RGCs), which appear at approximately embryonic day (E) 13 (Kriegstein and Götz, 2003). RGCs have their cell soma within the embryonic germinal zone, display a bipolar morphology with a single, elongated process that extends basally to the pial surface, and are distinguished from other radial cell populations, such as neuroepithelial cells, by displaying neuroepithelial and astroglial characteristics (Kriegstein and Götz, 2003). They serve an important structural role by supporting the migration of neurons born in the germinal zone to their appropriate location within the developing CNS (Rakic, 1972; de Carlos et al., 1996), and recent findings suggest that RGCs also function as neuronal and glial precursor cells (Götz et al., 2002; Malatesta et al., 2003). Despite their significant role in the development of the CNS, the generation of RGCs is not well understood.

Neural stem cells (NSCs) are self-renewing, multipotent cells that reside in the germinal zone and are thought to play a fundamental role in the generation of the diverse cell types of the CNS (Anderson, 2001). In the murine forebrain, NSCs appear as early

\footnotetext{
Received July 8, 2003; revised 0ct. 23, 2003; accepted 0ct. 24, 2003.

This work was supported by the Canadian Stroke Network and Stem Cell Network of the Canadian Networks of Centres of Excellence program. C.G. is a recipient of studentships from the Multiple Sclerosis Society of Canada and the Alberta Heritage Foundation for Medical Research (AHFMR); S.W. is an AHFMRSenior Scientist. We are extremely grateful to Drs. Carol Schuurmans and Derek van der Kooy for reviewing a previous version of this manuscript; to Emeka Enwere for preparing the supplementary movies; and to Karen Strunk and David Threadgill for supplying EGFR mutant mice.

Correspondence should be addressed to Samuel Weiss, Health Sciences Centre 2164,3330 Hospital Drive Northwest, University of Calgary, Calgary, Alberta, Canada, T2N 4N1. E-mail: weiss@ucalgary.ca.

Copyright $\odot 2003$ Society for Neuroscience $\quad$ 0270-6474/03/2311587-15\$15.00/0
}

as E8.5 and are characterized by their proliferation, in vitro, in response to fibroblast growth factor-2 (FGF-2) (Tropepe et al., 1999). At E11-12 a second population of NSCs appears that divide in response to either epidermal growth factor (EGF) or transforming growth factor $\alpha$ (TGF $\alpha$ ) (Tropepe et al., 1999). Given that growth factor-responsive NSCs are present in the CNS before the appearance of RGCs, it seems reasonable to propose that RGCs are the product of NSCs; however, such a relationship has yet to be established.

In the adult mammalian forebrain, a population of NSCs persists in the lateral ventricle subependyma and functions in the generation of new neurons destined for the olfactory bulb (Reynolds and Weiss, 1992; Lois and Alvarez-Buylla, 1994; Doetsch et al., 1999; Shingo et al., 2003). Despite the presence of adult NSCs, mammals are unable to regenerate damaged forebrain tissue, and indeed the progeny of adult forebrain NSCs appear to be specifically channeled to the olfactory bulb along a pathway enclosed by astrocyte processes (Doetsch et al., 1997). RGCs are no longer present in the adult brain (Voigt, 1989), and this may be a limiting factor in the ability of adult NSCs to direct their progeny to other regions of the brain. This is in stark contrast to the adult brains of lower vertebrates, where RGCs persist into adulthood and contribute to the ability of these animals to regenerate damaged CNS tissue (Bruni, 1998; Font et al., 2001; Zupanc, 2001; Götz et al., 2002). If NSCs are indeed the precursors to RGCs, environmental influences may limit their generation in the adult mammalian brain.

In the present study, we hypothesized that embryonic NSCs have the ability to give rise to functional RGCs and that understanding the signals that regulate the generation of RGCs may permit their production by NSCs in the adult CNS. We have 
identified EGF receptor (EGFR) signaling as being sufficient to promote the generation and differentiation of functional RGCs from embryonic forebrain NSCs in vitro. We found that EGF stimulated the generation of RGCs from adult NSCs in vitro and promoted the appearance of functional RGCs and radial ependymal cells in vivo within the adult forebrain.

\section{Materials and Methods}

Neurosphere cultures and sectioning for immunocytochemistry. Embryonic NSCs were cultured as neurospheres from tissue dissected from the ganglionic eminence of E14 CD-1 mice, as we have described recently in detail (Shimazaki et al., 2001). Morning of vaginal plug was designated E0.5. NSCs were cultured in the presence of FGF-2 (20 ng/ml; R \& D Systems, Minneapolis, MN) always together with heparin sulfate (HS) (2 $\mu \mathrm{g} / \mathrm{ml}$; Sigma, St. Louis, MO) or EGF (20 ng/ml; Peprotech) or TGF $\alpha[20$ $\mathrm{ng} / \mathrm{ml}$; Invitrogen (San Diego, CA) or Peprotech]. Second generation (pass 1) $7 \mathrm{~d}$ in vitro (DIV) neurospheres were differentiated intact in the RGC outgrowth assay (as described below) or were treated as follows. Neuropheres were rinsed in basal media, dissociated, and plated at a density of 200,000 cells per milliliter onto poly-L-ornithine-coated coverslips for $30 \mathrm{~min}$ in $300 \mu \mathrm{l}$ of basal media in 24-well plates (Nunc, Naperville, IL) to allow the cells to settle and subsequently be assessed for the presence of undifferentiated cells expressing RGC antigens. Alternatively, to assess differentiation of neurosphere cells expressing RGC antigens, dissociated cells were plated for 14-16 hr at a density of 100,000 cells per milliliter in $1 \mathrm{ml}$ of basal media or EGF media. Cells were then fixed in $4 \%$ paraformaldehyde and processed for immunocytochemistry.

Adult neurosphere cultures were generated as described by Shimazaki et al. (2001) in the presence of EGF media $(20 \mathrm{ng} / \mathrm{ml})$ from the periventricular region of 2- to 3-month-old CD-1 male mice. The adult neurospheres were then processed either for sectioning or for the RGC outgrowth assay as described below. For sectioning, the adult neurospheres were allowed to settle in $15 \mathrm{ml}$ Falcon tubes for 15-20 min, after which the media was removed and replaced with $4 \%$ paraformaldehyde for 20 min at room temperature. The paraformaldehyde was then aspirated off and replaced with $10 \%$ sucrose in PBS o/n at $4^{\circ} \mathrm{C}$, followed by $25 \%$ sucrose in PBS overnight at $4^{\circ} \mathrm{C}$. The sucrose was aspirated off of the pellet and replaced with O.C.T. compound (Miles, Elkhart, IN) and then embedded and frozen in a cryomold. Neurospheres were then cryosectioned at $14 \mu \mathrm{m}$ and processed for immunocytochemistry.

$R G C$ outgrowth assay. To assess the ability of different growth factors to control the elongation of RGCs, pass 1 neurospheres grown in FGF$2+$ HS, EGF, or TGF $\alpha$ for 7 DIV were allowed to settle for 15-20 min in a Falcon tube. The growth factor containing the media was aspirated off, and spheres were rinsed in basal media. Individual neurospheres, $150-$ $200 \mu \mathrm{m}$ in diameter, were transferred to poly-L-ornithine-coated 96-well plates (Nunc) containing FGF-2+HS, EGF, or TGF $\alpha$ media at a density of 30-40 spheres per well. The spheres were then cultured for an additional 5 DIV to allow for the formation of RGC processes between the spheres and then either quantified or processed for immunocytochemistry. To assess for the presence of migrating neurons, cells on the radial processes were observed over time by taking a photograph every $10 \mathrm{~min}$ for $4 \mathrm{hr}$ using a Leica DMIL inverted fluorescence microscope. To induce neuronal differentiation on the radial glial processes, growth media was removed and replaced with basal media for $48 \mathrm{hr}$. Processing for immunocytochemistry was performed by gently removing the growth media with a pipette and adding $4 \%$ paraformaldehyde in PBS for $30 \mathrm{~min}$. Wells were then gently washed with $\mathrm{PBS}$ by changing solutions using a pipette. All primary antibodies were applied for $48 \mathrm{hr}$ at $4^{\circ} \mathrm{C}$, and secondary antibodies were applied for $2 \mathrm{hr}$ at room temperature. Photos were taken through the bottom of the culture plates using the inverted fluorescent microscope.

MAPK inhibition study. Pass 1, 7 DIV EGF-derived E14 neurospheres were rinsed in basal media and then pretreated for $2 \mathrm{hr}$ in basal media containing either $5 \mu \mathrm{M}$ of the extracellular signal-related kinase (ERK)1/2 specific inhibitor UO126 (Cell Signaling Technology, Beverly, MA) (10 mM stock was diluted in DMSO) or the equivalent volume of DMSO (BDH Chemicals, Toronto, ON). After this pretreatment, the following experiments were performed. Neurospheres were dissociated, and cells were plated on poly-L-ornithine-coated coverslips at a concentration of 100,000 cells per milliliter in 24-well plates (Nunc) in the presence of either EGF+DMSO-containing media or EGF+UO126-containing media. After 14-16 hr, the cells were fixed and labeled for rapid cell 2 (RC2) to determine the percentage of $\mathrm{RC} 2$-expressing cells that adopted a radial morphology, defined as bipolar with one or both processes at least two cell bodies in length. Alternatively, 30-40 individual neurospheres, $150-$ $200 \mu \mathrm{m}$ in diameter, were plated in each well in 96-well plates coated with poly-L-ornithine in the presence of EGF media containing either UO126 or DMSO. After 3 DIV, the percentage of neurospheres that had extended RGC processes was determined.

Western blotting. Whole protein extractions from $10 \mathrm{ml}$ pass $1 \mathrm{E} 14$ neurosphere cultures were performed as described by Shingo et al. (2001). Pass 1 EGF-derived neurospheres were rinsed in basal media for $6 \mathrm{hr}$ to bring levels of phosphorylated mitogen-activated protein kinase (MAPK) to baseline (time 0 min was at the end of the $6 \mathrm{hr}$ ). Cells were then treated with FGF-2, EGF, or TGF $\alpha$ and harvested for protein after 5 and $15 \mathrm{~min}$. In each experiment, $25 \mu \mathrm{g}$ of protein was fractionated by $10 \%$ SDS-PAGE and transferred to nitrocellulose membranes (Bio-Rad, Hercules, CA). The membranes were blocked in blocking buffer $(25 \mathrm{~mm}$ Tris- $\mathrm{HCl}$, pH 7.5, $0.5 \mathrm{M} \mathrm{NaCl}, 0.3 \%$ Tween 20 , and 5\% nonfat skim milk) and incubated with the following primary antibodies overnight at $4^{\circ} \mathrm{C}$ (final concentration; source): rabbit anti-phospho MAPK (1:1000; Cell Biology Technologies); rabbit anti-MAPK (1:1000; Cell Biology Technologies); goat anti-actin (1:1000; Santa Cruz Biotechnology, Santa Cruz, CA). Blots were washed and probed with the appropriate peroxidase-conjugated secondary antibodies (1:5000; Jackson ImmunoResearch,West Grove, PA). Immunoreactivity was developed by enhanced chemiluminescence (Amersham Biosciences, Arlington Heights, IL).

Intracerebroventricular infusions. Intracerebroventricular infusions were performed as described by Shimazaki et al. (2001) using 2- to 3-month-old CD-1 male mice. FGF-2 $(33 \mu \mathrm{g} / \mathrm{ml})$ plus HS $(930 \mu \mathrm{g} / \mathrm{ml})$, EGF $(33 \mu \mathrm{g} / \mathrm{ml})$, TGF $\alpha(33 \mu \mathrm{g} / \mathrm{ml})$, or vehicle control ( $0.9 \%$ saline containing $1 \mathrm{mg} / \mathrm{ml}$ mouse serum albumin) infusions were performed intracerebroventricularly for $6 \mathrm{~d}$ at a rate of $0.5 \mu \mathrm{l} / \mathrm{hr}$ using an osmotic pump (Alzet 1007D; Alza Corporation, Palo Alto, CA). On the sixth day of infusion, all animals were injected with bromodeoxyuridine (BrdU; Sigma; $120 \mathrm{mg} / \mathrm{kg}$, i.p. dissolved in $0.007 \% \mathrm{NaOH}$ in phosphate buffer) every $2 \mathrm{hr}$ for $10 \mathrm{hr}$ and killed $0.5 \mathrm{hr}$ after the last injection. For $12 \mathrm{~d}$ EGF infusions, the pump was changed to a new full pump after $7 \mathrm{~d}$. Animals were killed by anesthetic overdose, perfused with $4 \%$ paraformaldehyde, cryosectioned, and analyzed by immunohistochemistry. Brains were serially sectioned in a one in seven series, $1014 \mu \mathrm{m}$ sections per slide, and one slide was counted for each animal for quantification purposes.

Immunocytochemistry and immunohistochemistry. Primary antibodies used were as follows: mouse anti-RC2 (neat; Developmental Hybridoma Bank; 1:100, a generous gift from Dr. P. LePrince, University of Liege, Belgium), mouse anti-nestin (neat; Developmental Hybridoma Bank), rabbit anti-nestin (1:100; a generous gift from Dr. U. Lendahl, Karolinska Institute, Sweden); rabbit anti-GFAP [1:400 (Biomedical Technologies, Stoughton, MA); 1:800 (Sigma)], mouse anti-TuJ1 (1:500; Sigma), mouse anti-Tau (1:100; PharMingen, San Diego, CA), mouse anti-Hu (1:20; Molecular Probes, Eugene, OR), rabbit anti-astrocyte-specific glutamate transporter (GLAST) (1:100; generous gift from M. Watanabe, Hokkaido University School of Medicine, Japan), mouse anti-Vimentin (1:100; Boehringer Mannheim, Mannheim, Germany), rabbit anti-brain lipid binding protein (BLBP) (1:800; generous gift from N. Heintz, Rockefeller University, New York, NY), rabbit anti-phospho signal transducer and activator of transcription-3 (STAT3) (1:100; Cell Biology Technologies), rabbit anti-phospho MAPK (1:100; Cell Biology Technologies), mouse anti-s100 $\beta$ (1:1000; Sigma), rat anti-BrdU (1:50; Harlan Seralab), rabbit anti-FGF receptor-1 (FGFR1) (1:50; Santa Cruz Biotechnology), rabbit anti-FGFR2 (1:50; Santa Cruz Biotechnology), sheep anti-EGFR (1:50, Biodesign), and goat anti-doublecortin (1:200; Santa Cruz Biotechnology). Terminal deoxynucleotidyl transferase-mediated biotinylated UTP nick end labeling (TUNEL) was performed using the Roche (Indianapolis, IN) in situ cell death kit according to the manufacturer's instructions. 
For immunohistochemical analysis on embryonic tissue sections, timed pregnant mice were killed, and the brain was removed from E14 embryos, fixed in $4 \%$ paraformaldehyde for $2 \mathrm{hr}$ on ice, and then cryoprotected with $25 \%$ sucrose overnight. For adult tissue sections, 6- to 8 -week-old mice were perfused with $4 \%$ paraformaldehyde, and the brains were dissected and placed in $4 \%$ paraformaldehyde overnight at $4^{\circ} \mathrm{C}$ and then cryoprotected overnight in $10 \%$, followed by $25 \%$ sucrose. All tissue was embedded in Tissue Tek O.C.T. compound (Sakura Finetek, Torrance, CA) and cryosectioned at $14 \mu \mathrm{m}$. Tissue was analyzed using antibodies listed previously. For BrdU staining, tissue sections were treated with $1 \mathrm{M} \mathrm{HCl}$ for $30 \mathrm{~min}$ at $60^{\circ} \mathrm{C}$ to denature cellular DNA, and sections were treated in ice-cold methanol for 6 min for RC2 staining. Primary antibodies were followed by incubation with fluorescein-, rhodamine-, or 7-amino-4-methylcoumarin-3-acetic acid-conjugated secondary antibodies against mouse, sheep, or rabbit IgG or by using biotin-conjugated secondary antibodies followed by $\mathrm{Cy} 3$-streptavidin (Jackson ImmunoResearch). Sections and coverslips were mounted and viewed or photographed with a Zeiss Axiophot fluorescence microscope. Confocal analysis was performed using an Olympus Fluoview BX-50 laser scanning confocal microscope.

Statistical analysis. Values are means \pm SEM. Statistical significance between groups was assessed using ANOVA and the Tukey-Kramer post hoc test, or paired $t$ test where noted.

\section{Results}

\section{Embryonic NSCs can generate prospective RGCs}

We hypothesized that RGCs are derived from NSCs during development and undertook an in vitro approach to determine whether NSCs have the capacity to give rise to RGCs and what signaling pathways might regulate this process. Our first objective was to identify putative extracellular signals that could stimulate the generation of RGCs from embryonic NSCs. The growth factors FGF-2 and EGF have been demonstrated to induce embryonic forebrain NSC proliferation. Thus, we asked whether these growth factors were also capable of inducing embryonic NSCs to generate the prospective radial cell populations of the developing forebrain, which include both RGCs and neuroepithelial cells (Kriegstein and Götz, 2003). NSCs were isolated from the ganglionic eminence of E14 murine embryos and cultured in vitro in the presence of FGF-2 or EGF. The resulting neurospheres (Reynolds et al., 1992; Reynolds and Weiss, 1996) generated by the NSCs in each condition were acutely dissociated and plated on poly-Lornithine. Cultures were examined for the presence of prospective radial cells by the markers RC2 (Misson et al., 1988) and nestin (Hockfield and McKay, 1985) 30 min after plating (Fig. $1 A-C)$. Both FGF-2 and EGF generated a similar number of RC2/ nestin-positive cells ( $29.5 \pm 9.2$ and $35.3 \pm 4.3 \%$, respectively, of the total cell population).

These results suggested that embryonic NSCs may be capable of generating prospective radial cell populations in response to either FGF-2 or EGF. Regardless of the initial growth factor conditions, however, very few RC2/nestin-expressing cells derived from the dissociated neurospheres adopted a radial morphology in basal media devoid of added growth factors, even after extended periods of differentiation on adherent substrates (data not shown). This prompted us to investigate putative extracellular and intracellular factors capable of signaling the differentiation of prospective radial cell populations from embryonic NSCs.

\section{EGF promotes RGC differentiation}

We hypothesized that growth factors, which promote the proliferative state of precursor cells, may also play a role in regulating radial cell differentiation. We first examined whether differentiated radial cells in the developing ventral forebrain in vivo expressed the receptors for the growth factors FGF-2 or EGF. Im-
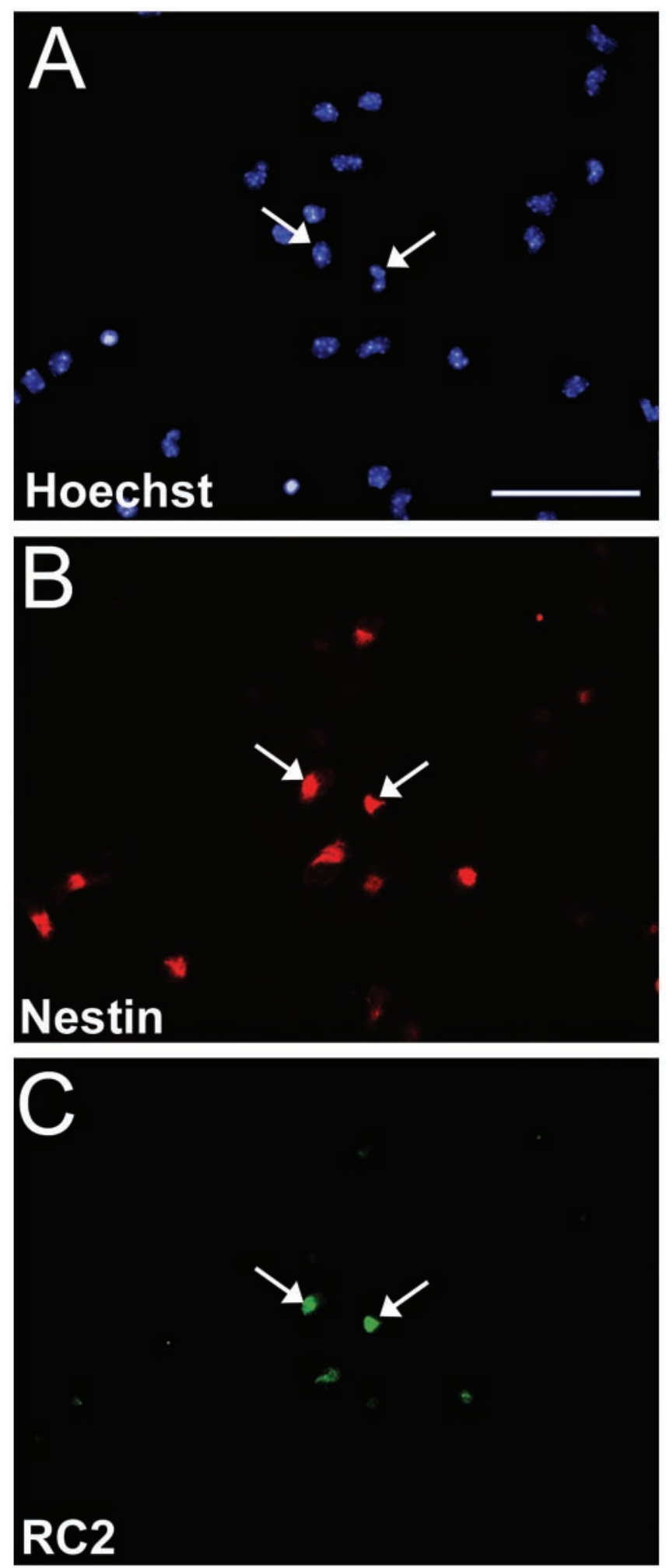

Figure 1. Growth factors stimulate the generation of prospective radial cells from embryonic NSCS. A-C, Embryonic NSCS, cultured in the presence of either FGF-2 or EGF, generated cells that coexpressed the radial cell markers nestin and RC2. Examples of double-labeled cells are indicated by arrows. Scale bar, $100 \mu \mathrm{m}$.

munohistochemical analysis revealed that radial cell populations residing in the lateral ganglionic eminence, identified by RC2 immunoreactivity, did not express the FGF-2 receptor FGFR1 at either E11.5 (beginning of neurogenesis) (Fig. 2A-C) or E14.5 
(peak of neurogenesis) (Fig. 2J-L). FGF-2, however, can also bind FGFR2 with high affinity (Miki et al., 1992). Analysis of FGFR2 expression revealed its presence on radial cells at both E11.5 (Fig. 2D-F) and E14.5 (Fig. 2M-O) in the lateral ganglionic eminence. Radial cell populations also expressed the EGFR at both E11.5 (Fig. $2 G-I$ ) and E14.5 (Fig. $2 P-R$ ). These findings are consistent with a possible role for both FGFR2 and EGFR signaling in the regulation of the differentiation of the radial cell populations residing in the developing ventral telencephalon.

We first focused on testing the putative action of EGF on RGC differentiation, given previous studies that have shown that EGFRs play a key role in glial cell differentiation (Burrows et al., 1997, 2000). Neurospheres originally generated in EGF were dissociated and then plated on an adhesive substrate for $14-16 \mathrm{hr}$ in the absence or presence of EGF. Counting of cells that both expressed RC2 and displayed an elongated, radial morphology revealed that EGF strongly promoted RGC differentiation. The percentage of radial RC2-expressing cells was increased by 7.5fold in the presence of EGF (basal media = $3.0 \pm 0.6 \%$; EGF media $=23.6 \pm 3.3 \%$; $n=3$; paired $t$ test, $p=0.02$ ) (see supplementary Fig. $1 A-D$, available at www.jneurosci.org). Further analysis revealed that all radial RC2-expressing cells generated in the EGF differentiation condition also expressed GLAST (supplementary Fig. $1 E, F)$ and therefore displayed both the neuroepithelial and astroglial characteristics indicative of RGCs. To address the possibility that EGF may be acting as a survival factor for RGCs, we compared the percentage of RC2-immunoreactive cells that labeled for the apoptotic indicator TUNEL in EGF media relative to that found in basal media. We found that after a $14-16 \mathrm{hr}$ culture period there was no difference in the percentage of RC2+/TUNEL + cells when comparing the EGF and basal media conditions (EGF media: $18.3 \pm 3.5 \%$; basal media: $16 \pm 3.9 \% ; n=3)$. These data suggest that EGF promotes the differentiation of RGCs rather than their survival.

Despite this apparent enhancement of RGC differentiation, these results did not establish the generation and differentiation of bona fide, functional RGCs capable of supporting neuronal migration. To examine this, we plated $\sim 30-40$ intact EGF-generated neurospheres on poly-L-ornithine, in the presence of either basal media or EGF-containing media for $5 \mathrm{~d}$ to monitor the formation of radial processes that support neuronal migration. We initially confirmed that this assay was appropriate for studying the differentiation of functional RGCs by examining the extension of elongated processes from and between individual neurospheres. In- tact neurospheres differentiated in basal media did not give rise to radial processes (Fig. 3A); however, neurospheres differentiated in the presence of EGF gave rise to long, thin processes that extended between adjacent neurospheres, occurring at a frequency of approximately one to two $(1.5 \pm 0.2)$ processes per neurosphere (Fig. $3 B)(n=4)$. Phase-contrast images suggested that the processes were actively supporting the migration of immature neurons (Fig. $3 B$, inset), similar to previous in vitro descriptions of RGCs supporting neuronal migration (Edmondson and Hat- 

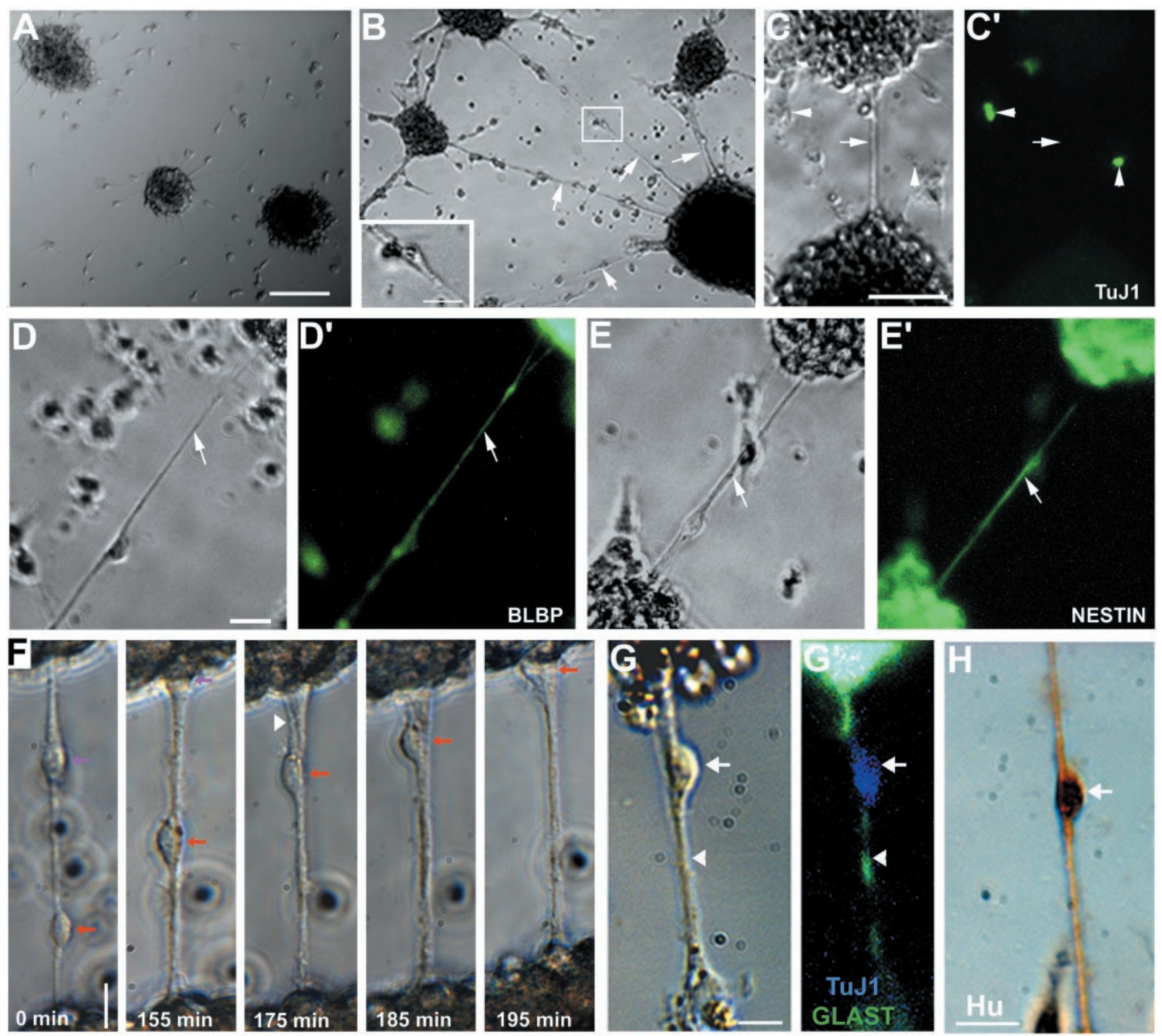

Figure 3. EGF promotes the generation and differentiation of cells from embryonic NSCs that antigenically, morphologically, and functionally resemble RGCS. $A$, Neurospheres grown in EGF and differentiated in basal media (see Materials and Methods) did not give rise to cells resembling RGCs $(n=3)$ Scale bar, $100 \mu \mathrm{m}$. $B$, Neurospheres grown in EGF and differentiated in EGF-containing media extended long, RGC-like processes (arrows) that appeared to support the migration of immature neurons. Scale bar: $B$, inset, $20 \mu \mathrm{m}$. C, $C^{\prime}, \mathrm{RGC}$-like processes did not express the neuronal marker TuJ1 (arrow in $C, C^{\prime}$; arrowheads indicate immunopositive cells. Scale bar, $50 \mu \mathrm{m} . D, E, R G C$-like processes expressed the RGC markers BLBP (D, $D^{\prime} ; s c a l e$ bar, $\left.20 \mu \mathrm{m}\right)$ and nestin $\left(E, E^{\prime}\right)$. Arrows indicate RGC process. F, RGC-like processes supported neuronal migration, as shown by time-lapse photography over $195 \mathrm{~min}$ (two individual migrating cells are indicated by purple and red arrows; white arrowhead indicates leading process of migrating neuron). Scale bar, $20 \mu \mathrm{m} . G, G^{\prime}, R G C$ processes, identified by expression of the RGC marker GLAST (green, arrowhead), supported the migration of cells identified as neurons using the neuron-specific marker TuJ1 (blue, arrow). Scale bar, $20 \mu \mathrm{m}$. H, Immature neurons could also be identified on RGC processes by the neuron-specific marker Hu. Scale bar, $20 \mu \mathrm{m}$.

ten, 1987; Feng et al., 1994; Anton et al., 1997); however, it has been suggested that immature neurons can also migrate on axons (Golden et al., 1997). To determine whether the long, thin processes were indeed RGC processes rather than axons, the expression of neuronal-axonal versus RGC markers was examined. The elongated processes that extended between neurospheres in response to EGF did not express the neuron-specific marker TuJ1 (Fig. $3 C, C^{\prime}$ ) or the axonal marker tau (data not shown) and therefore were likely not neuronal in nature; however, these processes did express the RGC markers BLBP (Fig. 3D, $D^{\prime}$ ) (Feng et al., 1994), nestin (Fig. 3E, $E^{\prime}$ ), GLAST (Fig. 3G, $G^{\prime}$ ) (Hartfuss et al., 2001), and vimentin (data not shown). These results confirmed that the EGF-induced processes, extending between neurospheres, morphologically and antigenically resemble the process extensions characteristic of RGCs, displaying both astroglial (BLBP and GLAST immunoreactivity) and neuroepithelial (nestin and vimentin immunoreactivity) characteristics (Kriegstein and Götz, 2003). To ask whether the RGC-like cells generated by NSCs were functional by virtue of their ability to support migration of immature neurons on their processes, we used time-lapse microscopy. We found that cells attached to RGC processes were indeed migrating (Fig. $3 F$ ) and had the characteristic morphology of motile neurons, with an elongated process extending in the direction of movement (Fig. 3F, white arrowhead in middle 
panel) (Edmondson and Hatten, 1987; Nadarajah and Parnavelas, 2002). Migrating cells appeared to move between the neurospheres, at times exiting one neurosphere and traveling along the glial process to enter a second neurosphere. To confirm a neuronal nature of the migrating cells, the EGF-containing media was removed and replaced with basal media for $48 \mathrm{hr}$ to allow for neuronal differentiation. After this treatment, cells in contact with RGC (GLAST-positive) processes expressed the neuronal markers TuJ1 (Fig. 3G, $G^{\prime}$ ) and $\mathrm{Hu}$ (Fig. $3 \mathrm{H}$ ). These findings demonstrate that EGF can promote the generation and differentiation of functional RGCs from embryonic NSCs.

\section{FGF-2 does not promote \\ RGC differentiation}

We next asked whether FGF-2 or a different EGFR ligand, TGF $\alpha$, could mimic the ability of EGF to promote RGC differentiation. To address this issue, neurospheres were generated from the E14 ganglionic eminence in the presence of FGF-2, EGF, or TGF $\alpha$, differentiated in the presence of the homotypic or a heterotypic growth factor, and the percentage of neurospheres extending at least one RGC process was quantified. Virtually none of the neurospheres gave rise to RGC processes when differentiated in the presence of FGF-2 (Fig. $4 A, D$ ), independent of their primary source; however, $>50 \%$ of neurospheres generated in FGF-2 gave rise to RGC processes when differentiated in the presence of either EGF $(54.9 \pm 5.1 \%)$ or TGF $\alpha$ $(51.0 \pm 7.0 \%)$. Similarly, $57.5 \pm 6.0 \%$ of EGF neurospheres gave rise to RGC processes when differentiated in EGF (Fig. $4 B, D)$, and $56.3 \pm 8.7 \%$ of TGF $\alpha$ neurospheres gave rise to RGC processes when differentiated in TGF $\alpha$ (Fig. 4C,D). No significant difference in the average number of RGC processes per process-bearing sphere was observed between the EGF and TGF $\alpha$ conditions (data not shown). These findings suggest that EGFR signaling is indeed necessary for RGC differentiation in vitro and that both EGF and TGF $\alpha$ support this process.

We hypothesized that the difference between FGF-2 and EGF-TGF $\alpha$ signaling, with respect to RGC differentiation, may be related to a differential activation of either the MAPK or STAT-3 signaling pathways. Both signaling pathways are activated by receptor tyrosine kinases (Marshall, 1995) and are thought to regulate precursor cell proliferation and the development of glial cell lineages during development (Bonni et al., 1997; Rajan and McKay, 1998). We first analyzed the expression of phosphorylated STAT3 (P-STAT3) and MAPK (P-MAPK) in the RGC population of the E14 forebrain. Surprisingly, P-STAT3 did not appear to be expressed within the germinal zone or the RGC population of the ventral forebrain (Fig. $4 E-G$ ) but was expressed within the developing cortical plate (Fig. $4 H$ ). In contrast, P-MAPK was particularly heavily expressed within the RGC

M
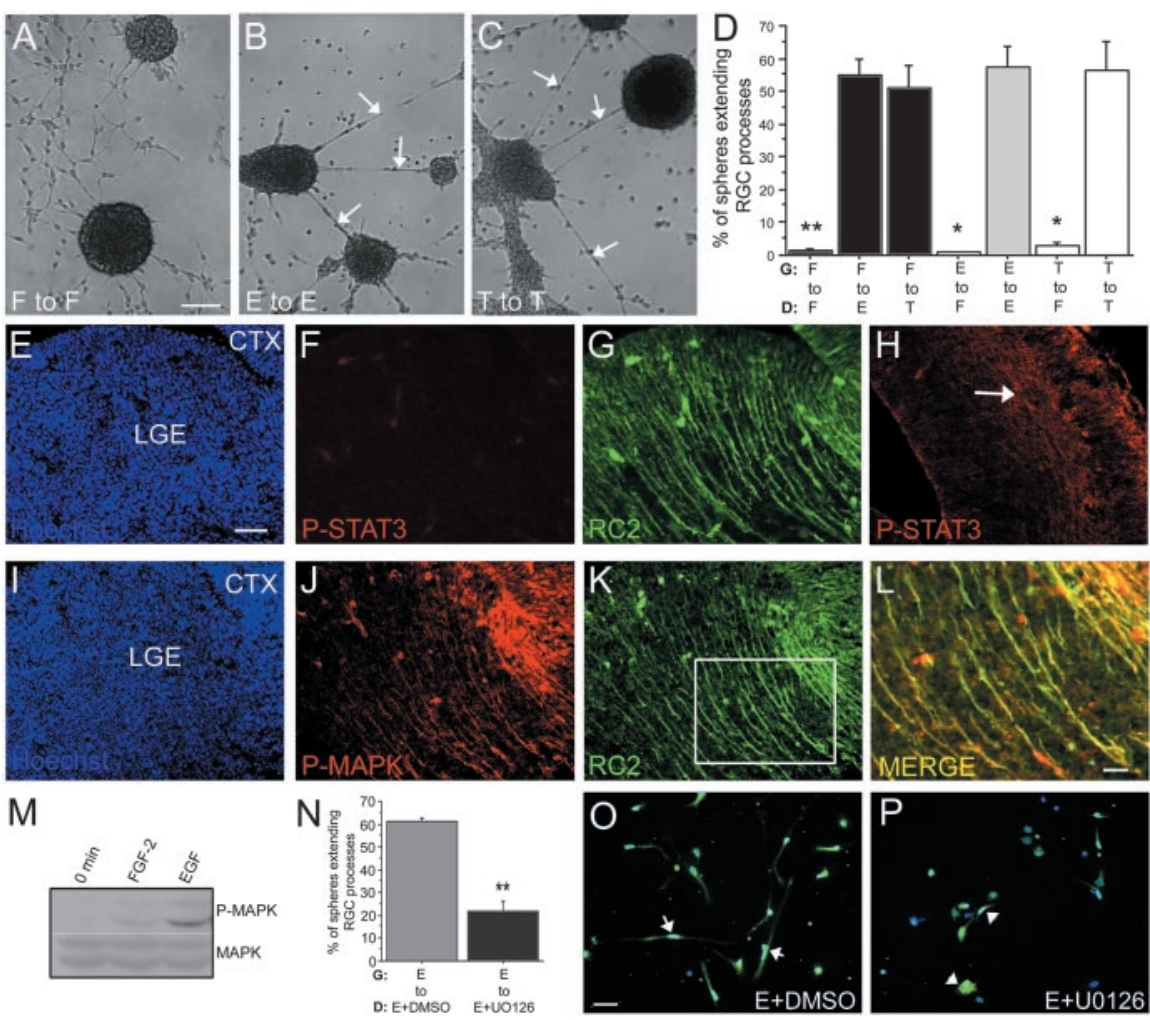

Figure 4. Regulation of RGC differentiation by growth factor signaling. $A-D$, Neurospheres grown (G) in FGF-2 (F), EGF (E), or (a) by RC2-expressing radial cell population of the E14 lateral ganglionic eminence (LGE). Scale bar, $50 \mu \mathrm{m}$. H, P-STAT3 expression for $6 \mathrm{hr}(6 \mathrm{hr}$ time point is time 0) and then pulsed with either FGF-2 or EGF for $15 \mathrm{~min}$, displayed decreased P-MAPK levels in the (a) $1 / 2$-specific inhibitor) during neurosphere differentiation significantly reduced the percentage that extended . $6.1 \%$ adopted a radial morphology in the presence of EGF+ DMSO after $14-16 \mathrm{hr}$ of differentiation ( 0 , arrows). Scale bar, $20 \mu \mathrm{m}$. Only $5.63 \pm 1.6 \%$, however, adopted a radial morphology in the presence of EGF + U0126 $(P$ examples of nonradial cells are indicated by arrowheads; Hoechst is shown in blue; paired $t$ test, $p=0.035 ; n=3$ ).

population of the E14 ventral telencephalon (Fig. 4 I-L), suggesting that MAPK activation rather than STAT3 activation may play a key role in regulating RGC differentiation.

Given that previous studies have suggested that qualitative and quantitative differences in MAPK activation appear to play a large role in the specific effects of different receptor tyrosine kinase signaling pathways (Marshall, 1995), we asked whether there may be differences between FGF-2 and EGF in MAPK activation that could potentially explain the inability of FGF-2 to induce RGC differentiation. To examine this possibility, EGF-generated neurospheres were rinsed in basal media for $6 \mathrm{hr}$ to allow P-MAPK levels to return to baseline (time 0 was the end of the 6 hr period). After this rinse, neurospheres were treated with either FGF-2 or EGF for 5 or $15 \mathrm{~min}$, and the level of P-MAPK relative to total MAPK was then examined by Western blotting. Decreased levels of P-MAPK were observed in the FGF-2 condition relative to EGF at both the $5 \mathrm{~min}$ (data not shown) and $15 \mathrm{~min}$ (Fig. 4M) time points. Previous dose-response studies in our lab found $20 \mathrm{ng} / \mathrm{ml}$ to be the maximal dose effect for FGF-2 in our 
culture system (S. Weiss, unpublished results). Therefore the lower level of P-MAPK that we observed in response to FGF-2 relative to EGF appears to be a characteristic of the FGF-2 signaling pathway rather than an issue of dose effect. These results suggest that lower levels of MAPK activation may at least partially underlie the inability of FGF-2 to induce RGC differentiation.

To test whether a robust activation of MAPK was indeed required for the differentiation of radial glia, whole EGF-generated neurospheres were differentiated in the presence of either EGF+DMSO or EGF+UO126 (an Erk1/2-specific MAPK inhibitor) for 3 DIV. The inhibition of MAPK activation resulted in a $65 \%$ decrease in the number of neurospheres that extended RGC processes in response to EGF (Fig. $4 N)(p=0.0084)$, suggesting a requirement for the activation of this pathway in RGC differentiation. To be certain that the observed decrease in RGC process extension was caused by the inhibition of RGC differentiation and not just an effect on proliferation or cell death within neurospheres, we performed a second experiment. EGFgenerated neurospheres were dissociated, and the cells were plated on poly-L-ornithine-coated coverslips in the presence of either EGF+DMSO or EGF+U0126 for 14-16 hr, after which the percentage of RC2-expressing cells that had adopted a radial morphology was assessed. In the presence of EGF+DMSO, $29.6 \pm 6.1 \%$ of RC2-expressing cells adopted a bipolar, radial morphology (Fig. 4O); however, the presence of the MAPK inhibitor U0126 resulted in a significant attenuation of the differentiation of these cells, reducing the percentage of radial RC2expressing cells to only $5.63 \pm 1.6 \%$ of the total RC2-expressing cell population (Fig. $4 P$ ) (paired $t$ test; $p=0.035 ; n=3$ ). These results suggest that the activation of MAPK signaling is required for RGC differentiation and that the low level of MAPK activation induced by FGF-2 likely underlies the lack of RGC differentiation in response to this signaling molecule.

\section{EGFR signaling promotes the generation and differentiation} of prospective RGCs in the adult forebrain

Although NSCs continue to be present within the adult forebrain, RGCs are not. Indeed, previous studies have suggested that the RGC-specific antigens BLBP and RC2 are absent from the adult forebrain (Misson et al., 1988; Feng et al., 1994; Chanas-Sacre et al., 2000). Given our findings that embryonic NSCs can give rise to RGCs, we hypothesized that adult NSCs retain this intrinsic capacity but the environment of the adult forebrain does not support their generation. We asked whether adult NSCs induced to proliferate and form neurospheres in the presence of EGF, which promotes the RGC fate, would generate cells expressing RGC antigens. Immunolabeling of cryosections of EGFgenerated adult neurospheres revealed cells that coexpressed the RGC markers RC2, BLBP, and nestin (Fig. 5A-F), in a manner identical to that seen with embryonic forebrain neurospheres (data not shown). Moreover, when populations of adult EGFgenerated neurospheres were differentiated in the continued presence of EGF, we observed a pattern of RGC process outgrowth and neuronal migration between neurospheres that was identical to that seen with embryonic neurospheres (data not shown). These results demonstrated that adult NSCs retain the capacity to give rise to RGCs in vitro. Because both the FGF (Gonzalez et al., 1995) and EGF (Seroogy et al., 1995) receptors are present in the periventricular region of the adult, we proceeded to ask whether RGCs might be generated in vivo within the adult subependyma.

To ask whether RGCs could be generated within the adult forebrain, growth factors were infused into the lateral ventricles
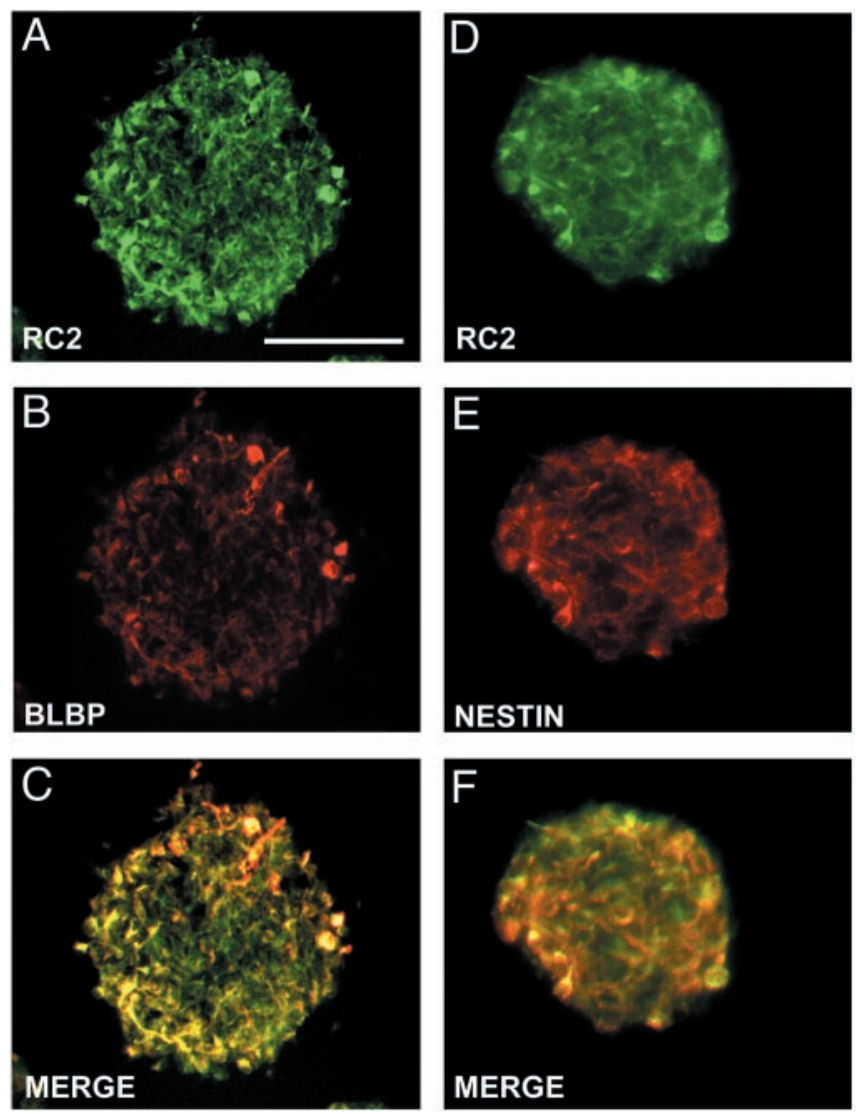

Figure 5. Adult NSCs generate prospective RGCs in response to EGF in vitro. Immunolabeled sections of adult neurospheres revealed cells that coexpressed the RGC markers RC2 and BLBP $(A, B)$, as well as RC2 and nestin $(D, E)$. Merged images are shown in C and $F$. Scale bar, $100 \mu \mathrm{m}$.

of adult male mice after which the presence of prospective RGCs was analyzed by immunohistochemistry. Examination of the lateral ventricle contralateral to the infusion revealed that vehicle control infusions did not give rise to prospective RGCs in the adult subependyma, as determined by the absence of RC2 expression (Fig. 6A) (higher magnification images are shown in supplementary Fig. $2 A, B$ ). The infusion of FGF-2 (Fig. $6 B$ ), EGF (Fig. $6 C$ ), or TGF $\alpha$ (Fig. 6D), however, resulted in the appearance of RC2-expressing cells around the circumference of the lateral ventricles. During mouse development, RC2-expressing RGCs do not normally express the astroglial marker GFAP until their transformation into astrocytes. To determine whether the RC2expressing cells generated in the infused mice displayed characteristics of astrocytes or rather resembled RGCs, we double labeled sections from infused animals with antibodies against RC2 and GFAP. After FGF-2 infusions, RC2-expressing cells in the subependyma coexpressed the astrocyte marker GFAP (Fig. 6E$G$ ); however, RC2-expressing cells in the subependyma did not express GFAP after either EGF (Fig. $6 H-J$ ) or TGF $\alpha$ infusions (Fig. $6 K-M$ ). These results suggested that prospective RGCs were being generated in the adult subependyma in response to EGF or TGF $\alpha$ (but not FGF-2) infusions.

Closer examination of the morphology of the RC2-expressing cells within the subependyma, after FGF-2 infusions, revealed a multipolar, astrocytic morphology consistent with the coexpression of the astrocyte marker GFAP (Fig. 7A). We used confocal microscopy to clearly discern the morphology of the RC2expressing cells generated within the subependyma of EGF- and TGF $\alpha$-infused animals. Rotations of Z-stacked confocal sections 
of RC2 staining in the subependyma of EGF-infused (Fig. 7B) or TGF $\alpha$-infused (data not shown) animals revealed the presence of single, elongated processes that extended from the ventricular surface into the surrounding parenchyma (also see supplementary movie 1). The RC2expressing cells within the subependyma of EGF-infused animals coexpressed the RGC markers BLBP (Fig. 7C-E) and nestin (Fig. $7 F-H)$. A small number of BLBPexpressing cells that did not coexpress RC2 were observed within the subependyma of control infused animals (supplementary Fig. 2C,D). Interestingly, some of the elongated RC2-expressing cells incorporated BrdU (Fig. 7I,J), indicating that like embryonic RGCs, these cells were mitotically active. Elongated RGC processes that extended from the ventricular surface were not confined to the proliferating adult subependyma, but some extended well into the surrounding parenchyma (Fig. $7 L)$. These findings demonstrate that EGF or TGF $\alpha$ (but not FGF-2) infusions promote the appearance of cells in the adult forebrain subependyma that morphologically and antigenically resemble RGCs.

\section{Newly generated RGCs support} neuronal migration in the adult CNS

It has been reported previously that the infusion of EGF or TGF $\alpha$, but not FGF-2, results in the migration of newly generated cells out of the subependyma and into the striatum (Craig et al., 1996). Given our observations that some newly generated RGC processes extended beyond the subependyma and into the striatum, we asked whether these RGCs play a role in supporting the migration of newly generated cells along their processes. Double labeling with $\mathrm{RC} 2$ and BrdU revealed examples of newly generated cells (with nuclei that had incorporated BrdU and had an elongated, flattened migratory morphology) (Fig. 8A) that appeared to be exiting the subependyma closely opposed to RGC processes (Fig. 8B,C), consistent with their proposed function as a migratory substrate. To determine whether these were indeed migrating neurons, we examined the expression of doublecortin, which specifically labels newly generated, migratory neurons (Arvidsson et al., 2002). In vehicle-infused animals, doublecortin-expressing neurons were located close to the ventricular surface, and none were observed to have a leading migratory process that extended within the transverse plane, consistent with their rostral movement toward the olfactory bulb (Fig. 8D) $(n=3)$. In animals that had been infused with EGF, however, $19.3 \pm 5.3 \%$ of doublecortin-expressing neurons $(n=3)$ exhibited an elongated, motile morphology within the transverse plane, and some of these cells appeared to be migrating out of the
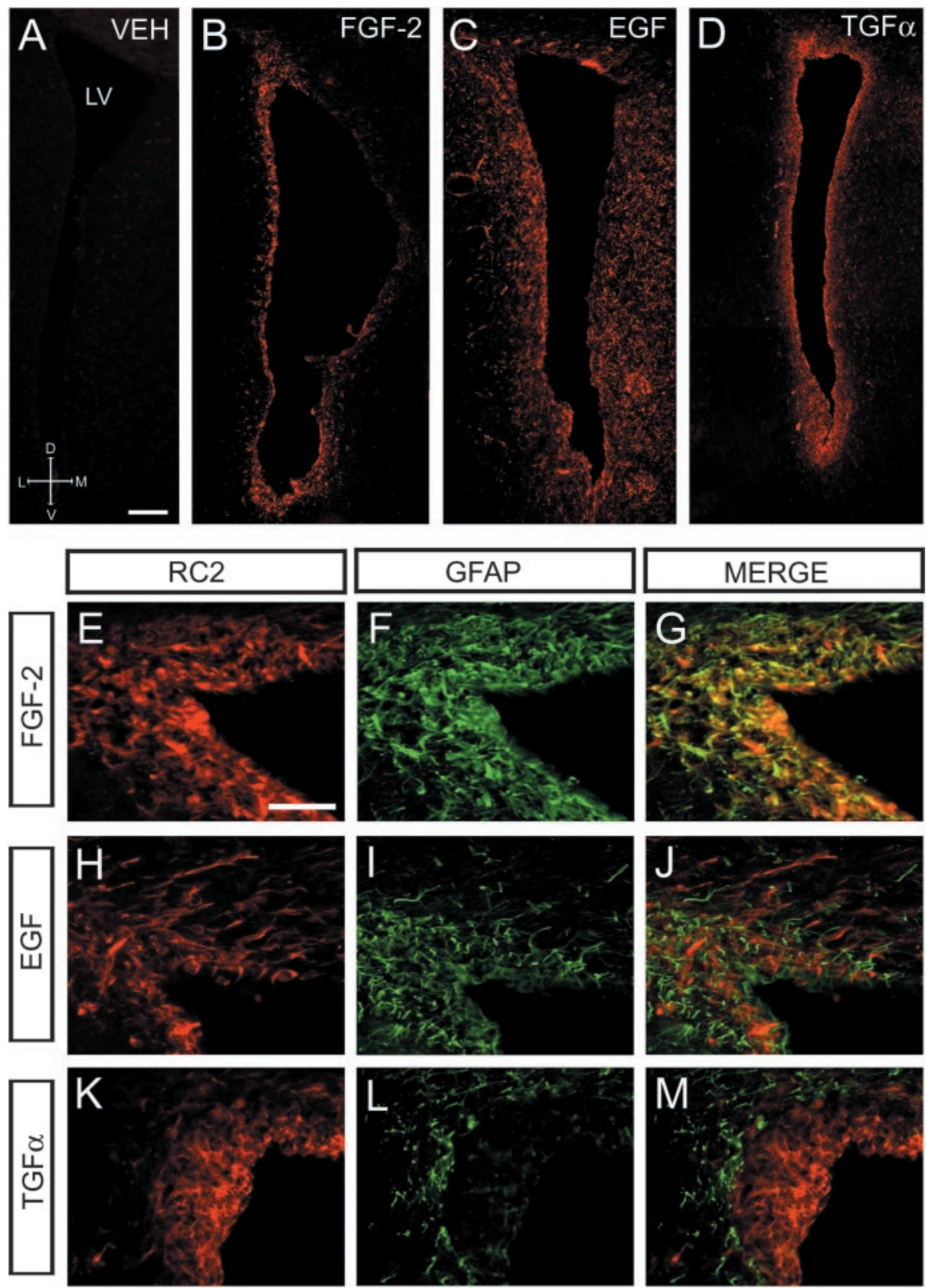

Figure 6. Infusion of EGF or TGF $\alpha$, but not FGF-2, into the lateral ventricles of the adult forebrain results in the generation of prospective $R G C S$. $A-D$, Prospective $R G C s$, identified by $R C 2$ expression, were not observed in the periventricular region of animals receiving vehicle (VEH) infusions $(A)$. In animals that received $6 \mathrm{~d}$ infusions of FGF-2 $(B)$, EGF $(C)$, or TGF $\alpha(D)$, however, $R C 2$-immunoreactive cells were observed around the entire circumference of the lateral ventricles. Scale bar (in $A$ ): $A-D, 100 \mu \mathrm{m}$. Similar patterns were seen in at least three infused animals in each condition. $E-M$, The relationship between $\mathrm{RC2}-$ immunoreactive cells and GFAP-immunoreactive astrocytes within the subependyma of FGF-2-infused ( $E-G)$, EGF-infused ( $H-J)$, and TGF $\alpha$-infused $(K-M)$ animals was examined. RC2-immunoreactive cells within FGF-2-infused animals coexpressed GFAP, suggesting that they were astrocytes; however, RC2 cells did not express GFAP, in either the EGF- or TGF $\alpha$-infused animals, which is characteristic of prospective RGCs. Scale bar: (in $E$ ), $E-M, 100 \mu \mathrm{m}$.

subependyma toward the striatum (Fig. $8 E, F$ ). To determine whether these neurons were using RGC processes as a migratory substrate, we double labeled tissue sections from EGFinfused animals with doublecortin and RC2. Figure $8 G-K$ shows confocal images of a doublecortin-expressing neuron with a migratory morphology, in which a single elongated leading process extended away from the neuronal cell body (Fig. 8G) is closely associated with an RC2-expressing RGC process (Fig. $8 H, I$ ). This association is indicative of a migratory support function by 

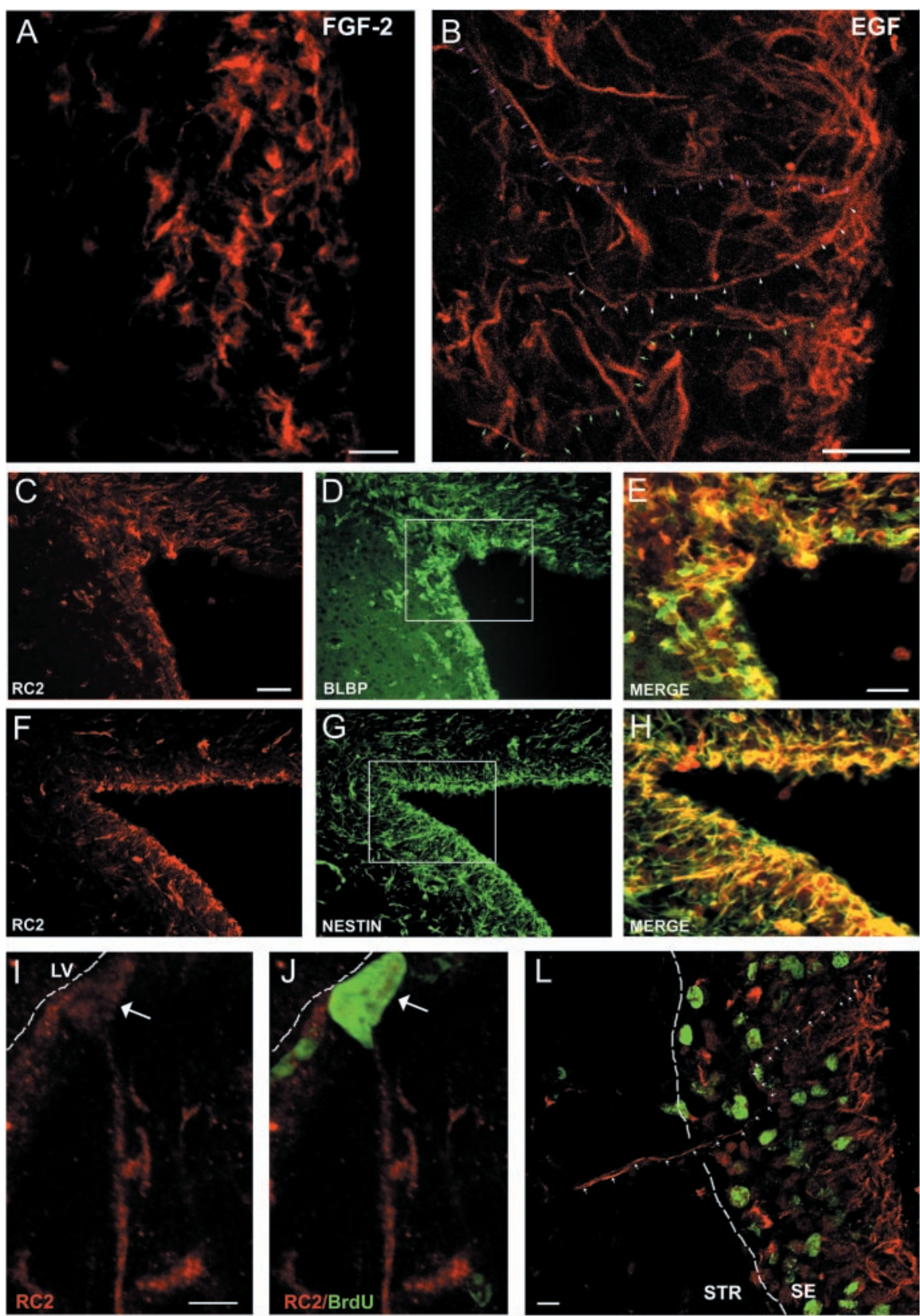

Figure 7. Infusions of EGF into the adult forebrain lateral ventricles induce the appearance of subependymal cells with the morphology and antigenic characteristics of RGCS. A, RC2-expressing cell population in FGF-2-infused animals displayed a multipolar, astrocytic morphology $(n=3)$. Scale bar, $20 \mu \mathrm{m}$. B, Z-stacked confocal images of RC2-expressing cells in EGF-infused animals revealed the presence of single, elongated $\mathrm{RC2}$-positive processes extending from the ventricular surface (individual processes are indicated with colored arrows; $n=5)$. Scale bar, $100 \mu \mathrm{m}$. (Also see supplementary movie 1.) $C-H, R C 2$-expressing cells in EGF-infused animals coexpressed the RGC markers BLBP and nestin. Scale bars: (in $C$ C, $F, 50 \mu \mathrm{m} ; D$, merge in $E, G$, merge in $H, 20 \mu \mathrm{m}$. I, J, Unipolar, RC2-expressing cells, which extended single, elongated radial processes perpendicular to the ventricular surface, incorporated BrdU. Scale bar, $5 \mu \mathrm{m}$. L, Example of a single, elongated RC2-expressing process (white arrows), extending from the ventricular surface laterally through and beyond the full extent of the subependyma (SE), illustrated here by the mitotically active BrdU-labeled precursors, into the neighboring striatum (STR). Scale bar, $10 \mu \mathrm{m}$.

the radial glial process for the migrating neuron. Closer analysis, by rotating the confocal image, revealed that the leading neuronal process wrapped around the RC2-expressing RGC process (Fig. $8 J, K)$ in a manner that is similar to previous descriptions of neurons migrating on RGCs during development (Rakic et al., $1974)$. Counting revealed that $35.3 \pm 1.5 \%(n=3)$ of the neurons migrating within the transverse plane, within EGF-infused animals, appeared to be using RGC processes to support their mi- gration. These findings suggest that many newly generated neurons within the EGFinfused adult forebrain appear to be using the RGC processes as a migratory substrate, supporting the contention that newly generated adult RGCs are functional in vivo.

\section{Adult ependymal cells adopt a radial morphology in response to EGFR signaling in vivo}

Adult ependymal cells, known to function in mediating the exchange of molecules between the brain parenchyma and the cerebrospinal fluid (Bruni, 1998), have been suggested to be descendants of the embryonic ventricular zone (Takahashi et al., 1996). Such a relationship is supported by recent studies that report that adult forebrain ependymal cells are NSCs (Johansson et al., 1999; Rietze et al., 2001). These findings, however, are the subject of great controversy, given that the results of other studies argue that these forebrain ependymal cells are not NSCs (Chiasson et al., 1999; Doetsch et al., 1999; Morshead and van der Kooy, 2001; Capela and Temple, 2002). Nevertheless, because nearly all ventricular zone precursors are radial in morphology during early development (Malatesta et al., 2000; Götz et al., 2002; Noctor et al., 2002), a putative relationship between these radial precursors and the adult ependyma remains possible. Given our results that indicate that EGFR signaling promotes the RGC phenotype, we asked whether EGFR activation of the ependymal cell population of the adult forebrain might modify their differentiated phenotype and induce them to take on a radial morphology.

The morphology of the ependymal cell population that lines the lateral ventricles of the forebrain was examined using the ependymal cell marker s100 $\beta$ (Chiasson et al., 1999). Because this marker also labels some astrocytes, however, we colabeled the adult forebrain with GFAP (Fig. 9A,B) and determined that $\mathrm{s} 100 \beta$ specifically labels ependymal cells (and not astrocytes) in the periventricular region of the lateral ventricles. The ependymal cell population of vehicle-infused animals was a single cell layer, immediately adjacent to the ventricles, with normal, cuboidal morphology (Fig. 9C). After FGF-2 infusions (Fig. 9D), the ependyma also generally remained cuboidal, although a very small number of cells $(2.2 \pm 1.0 \%)$ extended a short basal process away from the ventricular surface. Also, although $\mathrm{s} 100 \beta$ was not expressed in the subependyma of vehicle-infused controls (Fig. 9C), there was an upregulation of s100 $\beta$ in cells within the subependyma of FGF2-infused animals (Fig. 9D). This observation is consistent with our previous demonstration that FGF-2 infusion promoted as- 
trogliogenesis in the subependyma (Figs. $6 E-G, 7 A$ ). Remarkably, after EGF (Fig. 9E) and TGF $\alpha$ (Fig. 9F) infusions, $48.9 \pm 14.9$ and $66.9 \pm 5.9 \%$ of ependymal cells (Fig. $9 G)$, respectively, extended a single, long thin basal process away from the ventricular surface (also see supplementary movie 2). Double labeling of $s 100 \beta$ with the RGC markers BLBP (Fig. 9H), RC2 (Fig. 9I), and nestin (Fig. 9J) revealed that, although they displayed a radial morphology, ependymal cells did not express RGC antigens.

Closer analysis of EGF- and TGF $\alpha$ infused forebrains revealed some regional differences in the radial response of the ependymal cell population. Dorsally, many ependymal cells were found to have translocated their soma away from the ventricular surface and adopted a bipolar morphology (Fig. 10A,B). These cells left a short apical process and end foot contacting the ventricular surface and extended a basal process from the opposite side of the cell (Fig. $10 \mathrm{~B}$ ). Less frequently, ependymal cells along the medial aspect of the lateral ventricle were also observed to undergo this somal translocation away from the ventricular surface (Fig. 10C), and these cells also left a trailing apical process attached to an end foot at the ventricular surface. The end foot could be clearly distinguished from the soma of resident ependyma by the absence (Fig. 10C, white arrows) versus the presence (Fig. 10C, red arrows) of nuclei revealed by the nuclear marker Hoechst. Remarkably, somal translocation was never observed among ependymal cells residing on the lateral aspect of the ventricle, in either EGF- or TGF $\alpha$-infused forebrains (Fig. 10A) $(n=3)$; these cells extended only basal processes. Unlike the RGC processes, which often extended into the surrounding parenchyma, basal ependymal cell processes extended only to the limit of the growth factor-expanded subependyma (Fig. 10D).

To determine whether the radial ependymal cells that appeared in response to EGF or TGF $\alpha$ infusion were mitotically active, adult forebrains were infused with either EGF or TGF $\alpha$ for $6 \mathrm{~d}$; on the sixth day they received BrdU injections every $2 \mathrm{hr}$ for a total of $10 \mathrm{hr}$. Scanning confocal microscopy was used to quantify the number of ependymal cells that were immunopositive for both s100 $\beta$ and BrdU. In all animals examined, we were unable to find a single example of an ependymal cell that had incorporated BrdU (Fig. 10E-G). Although some ependymal cells appeared to have incorporated BrdU, rotations of confocal images revealed that the BrdU labeling was not within the cell soma (Fig. $10 \mathrm{H}-J$ ) and therefore was a different cell in close proximity. Thus, although many ependymal cells did apparently dedifferentiate and adopt a radial morphology in response to EGFR signaling, they did not become mitotically active.

\section{Discussion}

We tested the hypothesis that extrinsic signals are capable of regulating the generation and differentiation of RGCs from NSCs.
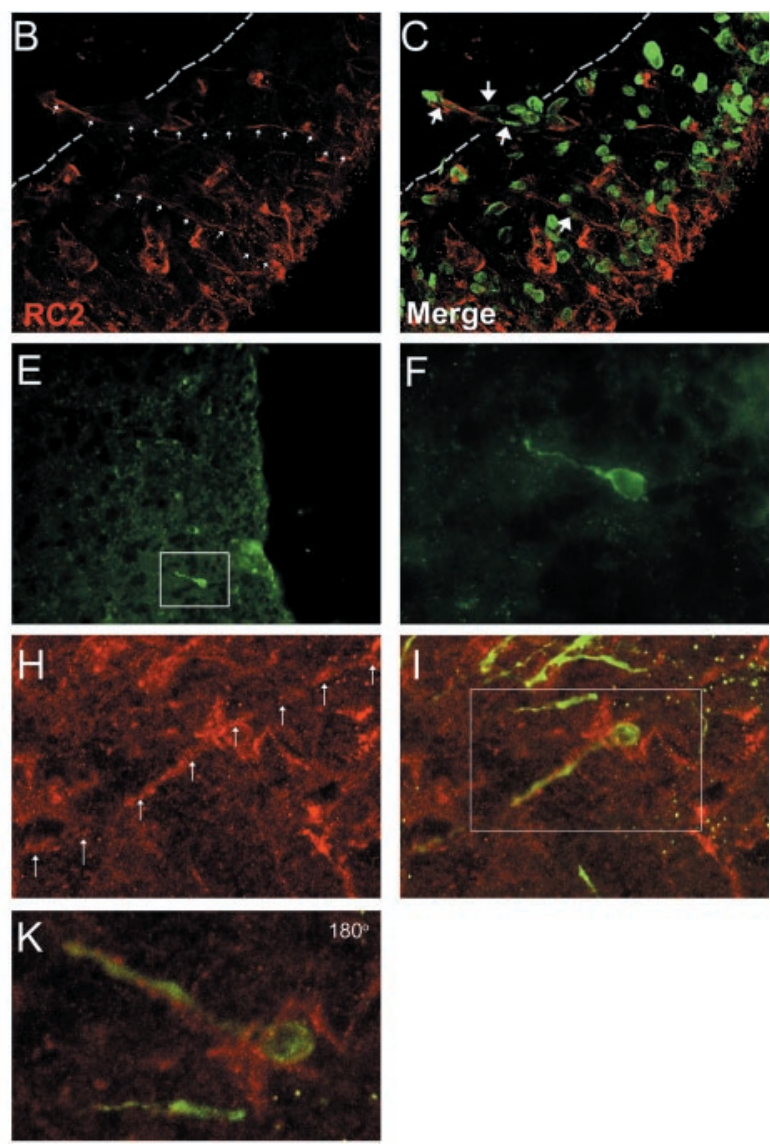

Figure 8. EGF-generated RGCS support the migration of newly generated neurons in the adult forebrain. $A-C$, Confocal microscopy of a DCX-labeled migratory neuron on the lateral border of the subependyma $(G)$, closely associated with an elongated $\mathrm{RC}$-expressing RGC process $(H, I)$. Enlarged confocal images reveal that the neuron cell body contacts the radial glial process and the leading neuronal process is wrapped around it $\left(J, 180^{\circ}\right.$ rotation in $\left.K\right)$. Scale bar, $20 \mu \mathrm{m}$.

Our results suggest the following: (1) both embryonic and adult NSCs are able to give rise to antigenically, morphologically, and functionally defined RGCs; (2) the generation and differentiation of RGCs by NSCs is differentially regulated by FGF-2 and EGFTGF $\alpha$ signaling; and (3) the activation of EGFR signaling within the adult forebrain germinal zone is sufficient to reestablish functional RGCs within the subependyma and, surprisingly, radial ependymal cells.

\section{Generation and differentiation of functional RGCs by NSCs} RGCs, displaying both neuroepithelial and astroglial characteristics, first appear in the forebrain at approximately E13, and their number appears to increase as neurogenesis proceeds (Misson et al., 1988; Hartfuss et al., 2001; Kriegstein and Götz, 2003). Our results suggest that both FGF and EGF-TGF $\alpha$-responsive embryonic NSCs could contribute to the process of generating and expanding the population of RGCs within the developing forebrain. Although little is known regarding the in vivo cellular origin of radial glia in the embryo, our findings can be placed into context with some recent studies, which have proposed lineage relationships between NSCs and RGCs. Regarding NSCs giving rise to RGCs, Hartfuss et al. (2001) reported that 95\% of the cells 

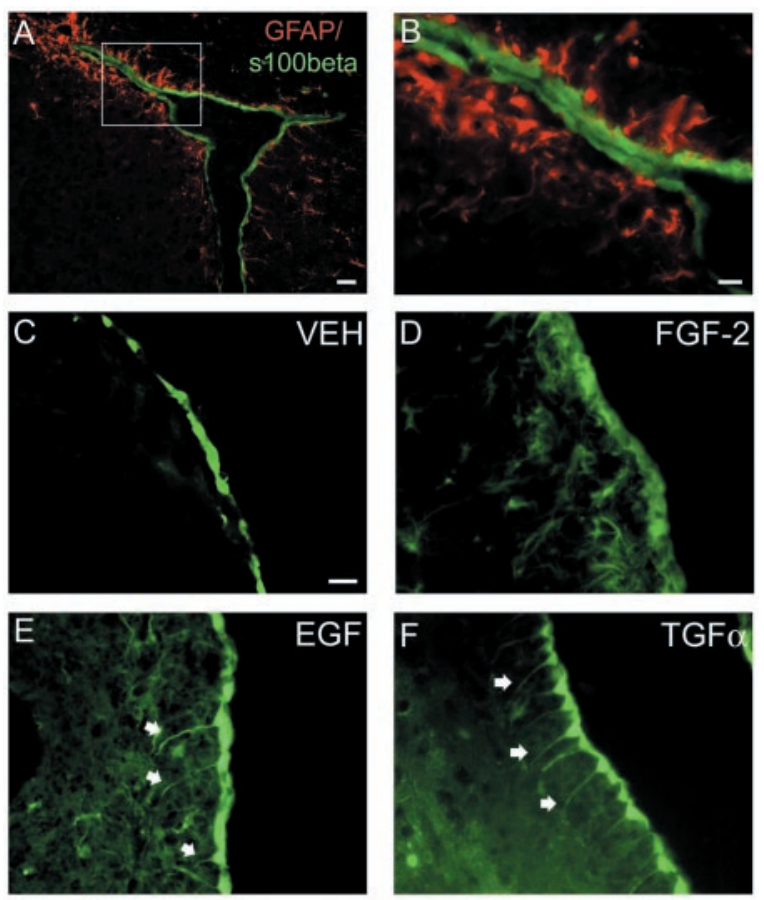

G
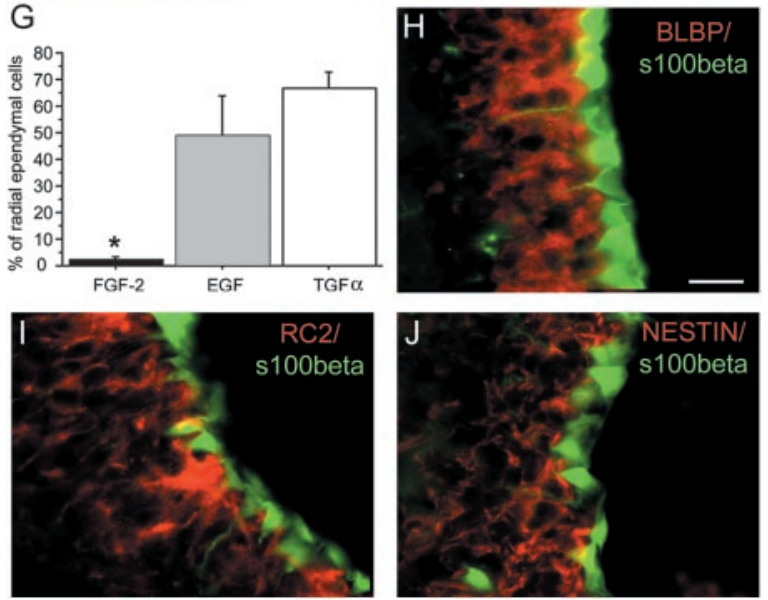

Figure 9. Adult forebrain ependymal cells extend radial processes but do not express RGC markers, after EGF or TGF $\alpha$ infusions. $A, B$, Double labeling confirms that $s 100 \beta$ specifically labels ependymal cells and not adjacent GFAP-expressing astrocytes in the subependyma of the adult forebrain. Scale bars: $A, 50 \mu \mathrm{m} ; B, 25 \mu \mathrm{m}$. $C-F$, Ependymal cells displayed a normal, cuboidal morphology in vehicle-infused (VEH) $(C$ and FGF-2-infused $(D)$ animals but extended single, basal processes perpendicular to the ventricular surface after either EGF ( $E$, arrows) or TGF $\alpha$ (F, arrows) infusions. Scale bar: (in $C)(-F, 20 \mu \mathrm{m}$. (Also see supplementary movie 2.) $G$, Counting of the numbers of ependymal cells that extended basal processes (given as a percentage of the total ependymal population) in growth factor-infused animals shows significantly fewer of these cells after FGF-2 infusions when compared with either EGF or TGF $\alpha$ infusions $\left({ }^{*} p=0.0146 ; n=3\right)$. See Results for details. $H-J$, Double labeling revealed that processbearing, s100 $\beta$-immunoreactive ependymal cells (green) did not express the RGC markers $\operatorname{BLBP}($ F; red), RC2 (G; red), or nestin (H; red). Scale bar (in $H)$ : $H-J, 20 \mu \mathrm{m}$.

within adult neurospheres were prospective RGCs on the basis of the expression of RC2, BLBP, and GLAST. This number seems unexpectedly high, however, given that $5 \%$ of the cells within adult forebrain neurospheres differentiate into oligodendrocytes, $>10 \%$ become neurons, and $30-60 \%$ become astrocytes (Reynolds and Weiss, 1992; Gritti et al., 1996). Furthermore, Hartfuss et al. (2001) did not ascertain whether NSCs simply give rise to cells that express RGC markers or whether these cells were indeed functional RGCs. Defining RGCs functionally, on the basis of their ability to support neuronal migration, is an important distinction because not all cells within the embryonic germinal zone that express RGC markers or have a radial morphology function in this way. In fact, it has been demonstrated that some cells with a radial morphology divide in the germinal zone to give rise to daughter cells that do not migrate on radial processes but undergo somal translocation to "pull" themselves into position in the developing brain (Miyata et al., 2001; Nadarajah et al., 2001). Indeed, numerous studies suggest that the radial cell populations of the developing brain are quite heterogeneous (Malatesta et al., 2000; Hartfuss et al., 2001; Malatesta et al., 2003; Kriegstein and Götz, 2003).

This issue of radial cell heterogeneity is also relevant regarding RGCs functioning as multipotent NSCs. Although there is abundant evidence for RGCs functioning as major precursor cells during forebrain development (Kriegstein and Götz, 2003), it is not yet clear whether some RGCs are also NSCs. It has been suggested that some RGCs may be NSCs on the basis of their ability to form neurospheres (Götz et al., 2002); however, the studies on which this suggestion was based relied on morphology and antigenic profile to identify RGCs, and therefore the relationship between functional RGCs that support neuronal migration and NSCs is still not known. Importantly, as discussed previously, some NSCs arise as early as E8.5, before the appearance of RGCs at E12-13, which suggests that some NSCs are not RGCs. It may be that some NSCs are radial neuroepithelial cells or perhaps even a rare population of nonradial precursors within the embryonic germinal zone (Fishell et al., 1993). In any case, the findings in our study support the hypothesis that NSCs give rise to functional RGCs, and additional studies into putative subpopulations and precise lineage relationships are clearly warranted.

Our results also shed light on the signals involved in promoting RGC differentiation. RGC differentiation involves both establishment of the bipolar or unipolar morphology as well as the extension of the long basal process toward the pia. In fact, a recent study has demonstrated that some RGCs continually extend new basal processes during neurogenesis (Miyata et al., 2001). Although we found that forebrain radial glia express both FGFR2 and EGFR, only signaling via the EGFR was able to promote RGC differentiation, both in vitro and in vivo. The inability of FGF-2 to promote RGC differentiation appears to be related, at least in part, to a decreased level of MAPK activation, which we have found to be heavily expressed by RGCs of the developing forebrain and required for RGC differentiation in vitro. Relevant to this point is a recent study by Ganat et al. (2002), which reported that chronic hypoxia promoted the appearance of RGCs in rat pups, and this correlated with increased levels of FGF-1 and FGF-2 expression. Our results strongly suggest that FGF signaling is not sufficient to induce the RGC fate, and therefore it may be of interest to determine whether EGFR signaling molecules are also upregulated in response to chronic hypoxia.

Our gain-of-function evidence for a role for EGFR signaling in RGC generation and differentiation is novel given that this signaling pathway has previously only been implicated in regulating the multipotency of NSCs and the generation of astrocytes during development (Burrows et al., 1997); however, our preliminary assessment of RGCs in EGFR null mutant mice revealed no obvious phenotype (our unpublished observations). Given the presence of RGCs within a broad range of phylogenetically diverse species and that a proper RGC scaffold is likely essential to the normal development of the brain, it seems reasonable to propose that redundant pathways may have evolved to ensure their normal differentiation. Previous studies have shown that other 
EGFR-related members of the erbB receptor family likely can also promote RGC differentiation (Anton et al., 1997; Rio et al., 1997; Schmid et al., 2003). In particular, erbB2 receptor mutant mice show abnormal RGC development (Anton et al., 1997); however, the erbB2 receptor has no known ligand and functions by heterodimerizing with each of the other erbB receptors, including the EGFR (Karunagaran et al., 1996; Graus-Porta et al., 1997; Deb et al., 2001). Thus, the phenotype of the erbB2 null mutant mouse may be the result of the disruption of multiple erbB receptor signaling pathways. We therefore suggest that the absence of a RGC defect in the EGFR knock-out mouse is attributable to compensating pathways, some of which likely also signal via erbB receptor family members.

EGFR signaling is not the first signaling system shown to be capable of inducing the RGC fate. The activation of Notch signaling was able to promote the RGC fate in embryos transfected with activated Notch1 (Gaiano et al., 2000); however, at later stages of development, Notch1 signaling promoted the generation of astrocytes rather than RGCs (Chambers et al., 2001), suggesting that Notch1 signaling alone is insufficient to act as an instructive determinant of the RGC fate. On the other hand, EGF signaling was sufficient to induce both embryonic and adult NSCs to produce functional RGCs in vitro. Moreover, in contrast to Notch actions, the ability of EGF to induce the appearance of functional RGCs in the adult subependyma in vivo illustrates an apparent lack of context dependence in inducing the RGC fate.

\section{RGC reestablishment in the adult forebrain subependyma}

Given the fundamental roles that RGCs play during development and their contribution to regenerative processes in lower vertebrates, it seems likely that the ability to reintroduce these cells in the adult germinal zone will benefit strategies to promote the endogenous regeneration of the CNS. This is particularly significant when placed in context with recent studies that have shown that the adult forebrain subependyma is the likely origin of new neurons that migrate to the striatum after stroke (Arvidsson et al., 2002; Kokaia and Lindvall, 2003). These remarkable findings have raised the question of how newly generated neurons within the subependyma and rostral migratory stream, which are ensheathed by glial processes that normally channel their migration to the olfactory bulb (Doetsch et al., 1997), can be redirected laterally into the striatum. Our findings suggest that RGCs generated within the adult subependyma are capable of directing lateral neuronal migration. Therefore, it may be that RGCs are involved in mediating the redirection of newly generated neurons within the subependyma after stroke. In support of this prospect is a recent study that showed that chronic hypoxia during the early postnatal period may induce the formation of RGCs in the rat forebrain (Ganat et al., 2002).

We reported previously that adult NSC proliferation induced by growth factor infusions resulted in newly generated neurons within the striatum, some of which migrated long distances away from the adult forebrain subependyma (Craig et al., 1996). In that study, long distance neuronal migration was observed in the striatum of animals that had been infused with either EGF or TGF $\alpha$ but not those that had received FGF-2 infusions. In agreement with these findings, a recent study demonstrated that the infusion of EGF enhanced the endogenous replacement of striatal neurons after stroke, but FGF-2 did not (Teramoto et al., 2003). Given that EGF infusion in unlesioned animals has been shown to inhibit neurogenesis in the subependyma (Kuhn et al., 1997; Doetsch et al., 2002), it seems likely that this increase in new neurons within the striatum of animals with strokes and EGF infusions is caused primarily by enhanced lateral migration. Taken together with the observations in the current study, 
whereby EGF or TGF $\alpha$ induced the generation of functional RGCs within the adult subependyma and FGF-2 did not, it seems reasonable to conclude that RGCs play an important role in redirected neurogenesis after both stroke and growth factor infusions.

It is noteworthy that some but not all of the BrdU-labeled cells or doublecortin-expressing neurons located outside the subependyma were closely associated with RGC processes. The nonRGC-associated cells may have already terminated RGC-guided migration or migrated via an alternative mechanism. Indeed, only a subpopulation of neurons generated within the ventral telencephalon migrate on RGCs during development (Halliday and Cepko, 1992). Also, previous studies show that very few new neurons successfully migrate into the striatum from the subependyma after either stroke (Arvidsson et al., 2002) or growth factor infusion (Craig et al., 1996). Therefore, it will be important to determine whether other factors, which either further promote RGC differentiation, such as neuregulin 1 (Schmid et al., 2003), or enhance neurogenesis, such as erythropoietin (Shingo et al., 2001), may further enhance the successful mobilization of newly generated neurons out of the adult subependyma to regions of brain injury.

Our results strongly argue that the absence of RGCs in the adult forebrain is likely caused, in part, by the environment of the adult CNS no longer supporting their generation; however, our results suggest that adult forebrain EGF-responsive NSCs do retain the capacity to give rise to RGCs. Then how does one reconcile the lack of RGC generation within the adult mammalian forebrain, when the results of an earlier study of TGF $\alpha$ hypomorphs suggested that TGF $\alpha$ mediates proliferation in the postnatal subependyma (Weickert and Blum, 1995)? In a more recent study, Tropepe et al. (1997) found that TGF $\alpha$ null mutant mice displayed decreased proliferation exclusively in the dorsolateral corner of the lateral ventricles; however, no decrease was observed in other subependymal regions in which NSCs are thought to reside (Doetsch et al., 1999). It may be that FGF-2 regulates the low level of intrinsic adult NSC proliferation and TGF $\alpha$ acts on more restricted progenitors. Indeed, forebrain adult NSCs proliferate in response to FGF-2 in culture (Gritti et al., 1996), and both FGFR1 and FGF-2 (Gonzalez et al., 1995) are expressed in the adult subependymal zone. In this scenario, when EGF or TGF $\alpha$ are infused into the lateral ventricles, they stimulate NSC proliferation, RGC generation, and differentiation in a manner that does not occur in their absence or restricted expression.

It has been suggested that, in some cases, mature astrocytes can dedifferentiate into RGCs in the appropriate environment (Hunter and Hatten, 1995). Thus, it may be that the RGCs observed in the subependyma of EGF- or TGF $\alpha$-infused animals may not be newly generated but rather are dedifferentiated astrocytes. RGCs within EGF- or TGF $\alpha$-infused animals expressed RC2 and did not express GFAP, however, and there was no apparent loss of GFAP-expressing cells in the subependyma of EGFor TGF $\alpha$-infused animals (compare GFAP expression in Fig. 6, $I$ and $J$, with Fig. 8, $A$ and $B$ ). This suggests that the GFAPexpressing astrocyte population of the subependyma did not dedifferentiate into RC2-expressing RGCs. Furthermore, our in vitro analysis demonstrated that adult NSCs induced to proliferate in response to EGF to form neurospheres gave rise to many newly generated cells that coexpressed the RGC markers RC2, BLBP, and nestin. Therefore, adult NSCs do proliferate in response to EGFR signaling to give rise to many new cells that express these markers and become functional RGCs. These findings suggest that the majority of the RC2-expressing cells, within the sub- ependyma of EGF- and TGF $\alpha$-infused animals, are newly generated.

\section{Insights into the putative origin and potential of adult forebrain ependymal cells}

An unexpected finding in this study was that $~ 50-65 \%$ of adult ependymal cells extended a basal process in response to the activation of EGFR signaling. No direct studies support the hypothesis that adult ependymal cells are derived from the radial cell populations within the developing brain germinal zone; however, the ability of these cells to adopt a radial morphology strongly argues that adult ependymal cells may be related to these earlier radial cell populations. It has been reported that a subpopulation of adult forebrain ependymal cells (tanycytes) normally extend basal processes; however, these cells are extremely rare in the forebrain (Doetsch et al., 1997). More recently, EGF was shown to induce an increase in the number of type B cells contacting the ventricles (Doetsch et al., 2002), and thus it may be that the radial, $s 100 \beta$-expressing cells that we observed were not ependymal cells but rather type B cells that had moved to the ventricular surface. We believe that this is unlikely, however, because type B cells normally proliferate in response to EGF (Doetsch et al., 1999), yet none of the $s 100 \beta$-expressing cells lining the ventricles proliferated in response to EGF in our study, which is consistent with the postmitotic character of adult ependymal cells (Chiasson et al., 1999; Doetsch et al., 1999) rather than type B cells. Thus, the numerous process bearing s $100 \beta$-expressing cells that we observed lining the lateral ventricles most likely are common cuboidal adult ependymal cells extending new processes in response to EGFR signaling.

Most noteworthy and intriguing was the region-specific ependymal response to EGF. Dorsal and medial ependymal cells responded to EGFR signaling by undergoing somal translocation away from the ventricular surface and adopting a pseudostratified organization, at times becoming bipolar. This reaction was not observed by ventrolateral ependymal cells, suggesting a difference between these two ependymal cell populations. During development, nearly all radial cells within the cortical germinal zone appear to function as precursor cells (Malatesta et al., 2000; Hartfuss et al., 2001; Miyata et al., 2001; Noctor et al., 2002). Additionally, a recent study has demonstrated that radial precursor cell populations of the dorsal telencephalon are far more neurogenic than those residing in the ventrolateral telencephalon (Malatesta et al., 2003). Given these findings, it will be of interest in the future to determine whether dorsal-medial ependymal cells are descended directly from cortical precursor cells and whether they retain the ability to function as precursor cells. Such analyses are particularly warranted given the unresolved controversy regarding adult ependymal cells. Several groups have presented evidence suggesting that adult forebrain ependymal cells may be NSCs (Johansson et al., 1999; Rietze et al., 2001) and that ependymal cells in the spinal cord can function as precursor cells (Johansson et al., 1999; Fu et al., 2003); however, the idea that adult ependymal cells are precursor cells, or even capable of proliferation, has been disputed vigorously by others (Chiasson et al., 1999; Doetsch et al., 1999; Morshead and van der Kooy, 2001; Capela and Temple, 2002). In any case, although our results demonstrate that either dorsal or ventral populations of adult forebrain ependymal cells have the capacity to apparently dedifferentiate and resemble primordial precursor cells, they did not proliferate in response to EGFR signaling. Therefore, other signaling molecules such as FGFR ligands, which are known to regulate precursor proliferation during cortical neurogenesis, may 
be required to drive ependymal cells to become mitotically active. This remains an intriguing and important avenue for future investigation.

\section{References}

Anderson DJ (2001) Stem cells and pattern formation in the nervous system: the possible versus the actual. Neuron 30:19-35.

Anton ES, Marchionni MA, Lee KF, Rakic P (1997) Role of GGF/neuregulin signaling in interactions between migrating neurons and radial glia in the developing cerebral cortex. Development 124:3501-3510.

Arvidsson A, Collin T, Kirik D, Kokaia Z, Lindvall O (2002) Neuronal replacement from endogenous precursors in the adult brain after stroke. Nat Med 8:963-970.

Bonni A, Sun Y, Nadal-Vicens M, Bhatt A, Frank DA, Rozovsky I, Stahl N, Yancopoulos GD, Greenberg ME (1997) Regulation of gliogenesis in the central nervous system by the JAK-STAT signaling pathway. Science 278:477-483.

Bruni JE (1998) Ependymal development, proliferation, and functions: a review. Microsc Res Tech 41:2-13.

Burrows RC, Wancio D, Levitt P, Lillien L (1997) Response diversity and the timing of progenitor cell maturation are regulated by developmental changes in EGFR expression in the cortex. Neuron 19:251-267.

Burrows RC, Lillien L, Levitt P (2000) Mechanisms of progenitor maturation are conserved in the striatum and cortex. Dev Neurosci 22:7-15.

Capela A, Temple S (2002) LeX/ssea-1 is expressed by adult mouse CNS stem cells, identifying them as nonependymal. Neuron 35:865-875.

Chambers CB, Peng Y, Nguyen H, Gaiano N, Fishell G, Nye JS (2001) Spatiotemporal selectivity of response to Notch1 signals in mammalian forebrain precursors. Development 128:689-702.

Chanas-Sacre G, Thiry M, Pirard S, Rogister B, Moonen G, Mbebi C, Verdiere-Sahuque M, Leprince P (2000) A 295-kDA intermediate filament-associated protein in radial glia and developing muscle cells in vivo and in vitro. Dev Dyn 219:514-525.

Chiasson BJ, Tropepe V, Morshead CM, van der Kooy D (1999) Adult mammalian forebrain ependymal and subependymal cells demonstrate proliferative potential, but only subependymal cells have neural stem cell characteristics. J Neurosci 19:4462-4471.

Craig CG, Tropepe V, Morshead CM, Reynolds BA, Weiss S, van der Kooy D (1996) In vivo growth factor expansion of endogenous subependymal neural precursor cell populations in the adult mouse brain. J Neurosci 16:2649-2658.

Deb TB, Su L, Wong L, Bonvini E, Wells A, David M, Johnson GR (2001) Epidermal growth factor (EGF) receptor kinase-independent signaling by EGF. J Biol Chem 276:15554-15560

de Carlos JA, Lopez-Mascaraque L, Valverde F (1996) Dynamics of cell migration from the lateral ganglionic eminence in the rat. J Neurosci 16:6146-6156.

Doetsch F, Garcia-Verdugo JM, Alvarez-Buylla A (1997) Cellular composition and three-dimensional organization of the subventricular germinal zone in the adult mammalian brain. J Neurosci 17:5046-5061.

Doetsch F, Caille I, Lim DA, Garcia-Verdugo JM, Alvarez-Buylla A (1999) Subventricular zone astrocytes are neural stem cells in the adult mammalian brain. Cell 97:703-716.

Doetsch F, Petreanu L, Caille I, Garcia-Verdugo JM, Alvarez-Buylla A (2002) EGF converts transit-amplifying neurogenic precursors in the adult brain into multipotent stem cells. Neuron 36:1021-1034.

Edmondson JC, Hatten ME (1987) Glial-guided granule neuron migration in vitro: a high-resolution time-lapse video microscopic study. J Neurosci 7:1928-1934.

Feng L, Hatten ME, Heintz N (1994) Brain lipid-binding protein (BLBP): a novel signaling system in the developing mammalian CNS. Neuron 12:895-908.

Fishell G, Mason CA, Hatten ME (1993) Dispersion of neural progenitors within the germinal zones of the forebrain. Nature 362:636-638.

Font E, Desfilis E, Perez-Canellas MM, Garcia-Verdugo JM (2001) Neurogenesis and neuronal regeneration in the adult reptilian brain. Brain Behav Evol 58:276-295.

Fu H, Qi Y, Tan M, Cai J, Hu X, Liu Z, Jensen J, Qiu M (2003) Molecular mapping of the origin of postnatal spinal cord ependymal cells: evidence that adult ependymal cells are derived from Nkx6.1+ ventral neural progenitor cells. J Comp Neurol 456:237-244.
Gaiano N, Nye JS, Fishell G (2000) Radial glial identity is promoted by Notch1 signaling in the murine forebrain. Neuron 26:395-404.

Ganat Y, Soni S, Chacon M, Schwartz ML, Vaccarino FM (2002) Chronic hypoxia up-regulates fibroblast growth factor ligands in the perinatal brain and induces fibroblast growth factor-responsive radial glial cells in the sub-ependymal zone. Neuroscience 112:977-991.

Golden JA, Zitz JC, McFadden K, Cepko CL (1997) Cell migration in the developing chick diencephalon. Development 124:3525-3533.

Gonzalez AM, Berry M, Maher PA, Logan A, Baird A (1995) A comprehensive analysis of the distribution of FGF-2 and FGFR1 in the rat brain. Brain Res 701:201-226.

Götz M, Hartfuss E, Malatesta P (2002) Radial glial cells as neuronal precursors: a new perspective on the correlation of morphology and lineage restriction in the developing cerebral cortex of mice. Brain Res Bull 57:777-788.

Graus-Porta D, Beerli RR, Daly JM, Hynes NE (1997) ErbB-2, the preferred heterodimerization partner of all ErbB receptors, is a mediator of lateral signaling. EMBO J 16:1647-1655.

Gritti A, Parati EA, Cova L, Frolichsthal P, Galli R, Wanke E, Faravelli L, Morassutti DJ, Roisen F, Nickel DD, Vescovi AL (1996) Multipotential stem cells from the adult mouse brain proliferate and self-renew in response to basic fibroblast growth factor. J Neurosci 16:1091-1100.

Halliday AL, Cepko CL (1992) Generation and migration of cells in the developing striatum. Neuron 9:15-26.

Hartfuss E, Galli R, Heins N, Götz M (2001) Characterization of CNS precursor subtypes and radial glia. Dev Biol 229:15-30.

Hockfield S, McKay RD (1985) Identification of major cell classes in the developing mammalian nervous system. J Neurosci 5:3310-3328.

Hunter KE, Hatten ME (1995) Radial glial cell transformation to astrocytes is bidirectional: regulation by a diffusible factor in embryonic forebrain. Proc Natl Acad Sci USA 92:2061-2065.

Johansson CB, Momma S, Clarke DL, Risling M, Lendahl U, Frisen J (1999) Identification of a neural stem cell in the adult mammalian central nervous system. Cell 96:25-34.

Karunagaran D, Tzahar E, Beerli RR, Chen X, Graus-Porta D, Ratzkin BJ, Seger R, Hynes NE, Yarden Y (1996) ErbB-2 is a common auxiliary subunit of NDF and EGF receptors: implications for breast cancer. EMBO J $15: 254-264$.

Kokaia Z, Lindvall O (2003) Neurogenesis after ischaemic brain insults. Curr Opin Neurobiol 13:127-132.

Kriegstein AR, Götz M (2003) Radial glia diversity: a matter of cell fate. Glia 43:37-43.

Kuhn HG, Winkler J, Kempermann G, Thal LJ, Gage FH (1997) Epidermal growth factor and fibroblast growth factor-2 have different effects on neural progenitors in the adult rat brain. J Neurosci 17:5820-5829.

Lois C, Alvarez-Buylla A (1994) Long-distance neuronal migration in the adult mammalian brain. Science 264:1145-1148.

Malatesta P, Hartfuss E, Götz M (2000) Isolation of radial glial cells by fluorescent-activated cell sorting reveals a neuronal lineage. Development 127:5253-5263.

Malatesta P, Hack MA, Hartfuss E, Kettenmann H, Klinkert W, Kirchhoff F, Götz M (2003) Neuronal or glial progeny: regional differences in radial glia fate. Neuron 37:751-764.

Marshall CJ (1995) Specificity of receptor tyrosine kinase signaling: transient versus sustained extracellular signal-regulated kinase activation. Cell 80:179-185.

Miki T, Bottaro DP, Fleming TP, Smith CL, Burgess WH, Chan AM, Aaronson SA (1992) Determination of ligand-binding specificity by alternative splicing: two distinct growth factor receptors encoded by a single gene. Proc Natl Acad Sci USA 89:246-250.

Misson JP, Edwards MA, Yamamoto M, Caviness VS Jr (1988) Identification of radial glial cells within the developing murine central nervous system: studies based on a new immunohistochemical marker. Brain Res Dev Brain Res 44:95-108.

Miyata T, Kawaguchi A, Okano H, Ogawa M (2001) Asymmetric inheritance of radial glial fibers by cortical neurons. Neuron 31:727-741.

Morshead CM, van der Kooy D (2001) A new "spin" on neural stem cells? Curr Opin Neurobiol 11:59-65.

Nadarajah B, Parnavelas JG (2002) Modes of neuronal migration in the developing cerebral cortex. Nat Rev Neurosci 3:423-432.

Nadarajah B, Brunstrom JE, Grutzendler J, Wong RO, Pearlman AL (2001) 
Two modes of radial migration in early development of the cerebral cortex. Nat Neurosci 4:143-150.

Noctor SC, Flint AC, Weissman TA, Wong WS, Clinton BK, Kriegstein AR (2002) Dividing precursor cells of the embryonic cortical ventricular zone have morphological and molecular characteristics of radial glia. J Neurosci 22:3161-3173.

Rajan P, McKay RD (1998) Multiple routes to astrocytic differentiation in the CNS. J Neurosci 18:3620-3629.

Rakic P (1972) Mode of cell migration to the superficial layers of fetal monkey neocortex. J Comp Neurol 145:61-83.

Rakic P, Stensas LJ, Sayre E, Sidman RL (1974) Computer-aided threedimensional reconstruction and quantitative analysis of cells from serial electron microscopic montages of foetal monkey brain. Nature 250:31-34.

Reynolds BA, Weiss S (1992) Generation of neurons and astrocytes from isolated cells of the adult mammalian central nervous system. Science 255:1707-1710.

Reynolds BA, Weiss S (1996) Clonal and population analyses demonstrate that an EGF-responsive mammalian embryonic CNS precursor is a stem cell. Dev Biol 175:1-13.

Reynolds BA, Tetzlaff W, Weiss S (1992) A multipotent EGF-responsive striatal embryonic progenitor cell produces neurons and astrocytes. J Neurosci 12:4565-4574.

Rietze RL, Valcanis H, Brooker GF, Thomas T, Voss AK, Bartlett PF (2001) Purification of a pluripotent neural stem cell from the adult mouse brain. Nature 412:736-739.

Rio C, Rieff HI, Qi P, Khurana TS, Corfas G (1997) Neuregulin and erbB receptors play a critical role in neuronal migration. Neuron 19:39-50.

Schmid RS, McGrath B, Berechid BE, Boyles B, Marchionni M, Sestan N, Anton ES (2003) Neuregulin 1-erbB2 signaling is required for the establishment of radial glia and their transformation into astrocytes in cerebral cortex. Proc Natl Acad Sci USA 100:4251-4256.

Seroogy KB, Gall CM, Lee DC, Kornblum HI (1995) Proliferative zones of postnatal rat brain express epidermal growth factor receptor mRNA. Brain Res 670:157-164.

Shimazaki T, Shingo T, Weiss S (2001) The ciliary neurotrophic factor/leukemia inhibitory factor/gp130 receptor complex operates in the maintenance of mammalian forebrain neural stem cells. J Neurosci 21:7642-7653.

Shingo T, Sorokan ST, Shimazaki T, Weiss S (2001) Erythropoietin regulates the in vitro and in vivo production of neuronal progenitors by mammalian forebrain neural stem cells. J Neurosci 21:9733-9743.

Shingo T, Gregg C, Enwere E, Fujikawa H, Hassam R, Geary C, Cross JC, Weiss S (2003) Pregnancy-stimulated neurogenesis in the adult female forebrain mediated by prolactin. Science 299:117-120.

Takahashi T, Nowakowski RS, Caviness VS Jr (1996) The leaving or Q fraction of the murine cerebral proliferative epithelium: a general model of neocortical neuronogenesis. J Neurosci 16:6183-6196.

Teramoto T, Qiu J, Plumier JC, Moskowitz MA (2003) EGF amplifies the replacement of parvalbumin-expressing striatal interneurons after ischemia. J Clin Invest 111:1125-1132.

Tropepe V, Craig CG, Morshead CM, van der Kooy D (1997) Transforming growth factor-alpha null and senescent mice show decreased neural progenitor cell proliferation in the forebrain subependyma. J Neurosci 17:7850-7859.

Tropepe V, Sibilia M, Ciruna BG, Rossant J, Wagner EF, van der Kooy D (1999) Distinct neural stem cells proliferate in response to EGF and FGF in the developing mouse telencephalon. Dev Biol 208:166-188.

Voigt T (1989) Development of glial cells in the cerebral wall of ferrets: direct tracing of their transformation from radial glia into astrocytes. J Comp Neurol 289:74-88.

Weickert CS, Blum M (1995) Striatal TGF-alpha: postnatal developmental expression and evidence for a role in the proliferation of subependymal cells. Brain Res Dev Brain Res 86:203-216.

Zupanc GK (2001) A comparative approach towards the understanding of adult neurogenesis. Brain Behav Evol 58:246-249. 